\title{
Analysis of Metal Plate Connected Wood Truss Assemblies Under Out-of- Plane Loads
}

\author{
Milad Mohamadzadeh \\ Thesis submitted to the faculty of the \\ Virginia Polytechnic Institute and State University \\ in partial fulfillment of the requirements for the degree of
}

\author{
MASTER OF SCIENCE \\ In \\ FOREST PRODUCTS \\ Daniel P. Hindman, Chair \\ Joseph R. Loferski \\ Cristopher D. Moen
}

\author{
July 21, 2014 \\ Blacksburg, VA
}

Keywords: Metal Plate Connected Wood Trusses, Personal Fall Arrest System, Residential Construction, Visual Analysis Software, Joint Stiffness, Modeling Validation. 


\title{
Analysis of Metal Plate Connected Wood Truss Assemblies Under Out-of- Plane Loads \\ Milad Mohamadzadeh
}

\begin{abstract}
$\underline{\text { Abstract }}$
In 2012, falls from elevation in construction industry represented $36 \%$ of the total fatalities. The Occupational Safety and Health Administration requires workers to use fall protection systems where workers are 6 feet or more above a lower level. Anchors for fall protection systems attached to roof trusses may cause out-of-plane loading on these structures. Metal plate connected wood trusses (MPCWT) are not designed to carry out-of-plane loads and MPCWT performance under these loads are not evaluated in the design process.

The goal of this research is to model and analyze MPCWT assemblies under out-of-plane loads. The rotational stiffness of truss-wall connections, and truss bracing elements are included in the structural component model. Previous experimental data of fall arrest anchor loading were used for model validation. A parametric study considering loading location, joint stiffness and dimension of trusses was conducted.

The structural analog of the MPCWT assemblies were found to have first truss deflections within $4 \%$ difference, thereby the models were validated. From parametric study results, the load location was not changed the ultimate deflection in the truss assembly by maximum value of $9 \%$. Out-of-plane joint stiffness was the parameter that caused a large difference in the deflection results, when the joists were assumed as either rigid or simple connections. The rotational stiffness of lateral and diagonal bracing should be included as model inputs for the accurate representation of experimental behavior. Truss lengths increased the deflection at the top chord of the first truss in the assembly as truss width increased.
\end{abstract}




\section{Acknowledgements}

I would like to use these two pages to express my appreciation to important ones in my life who helped me in the past two years, when I worked on my masters, and before.

First and foremost, God was the only one who took care of me and inspired me in moment of disappointments and fears. As before, I'm consistent on my faith and need your continues support for every single moment in my future life, THANKS A LOT!

I would like to wholeheartedly express my many thanks to my family; father, mother and brother who taught me how to live and be strong. My first 23 years of life in Iran were the years that I learned how to never give up and try tireless to reach my goals and do whatever I can to be a useful person for the society and also how to behave and respect others. Especial thanks to my mother, Tahereh, without your helps and encouragements I could never reach to where I am today. I can only say, you are the best mom in the world! Thanks!

Dr. Hindman, I always remember your statement, after I told you that my goal is to be a structural engineer; you said; "If you want to be a structural engineer, you need to know concrete and steel as well as wood!". You are one of the best advisors and friends that a young man could find. Thanks for everything you did for me, from first stages that you trust me and providing financial supports for my education, all the way to help me getting Ph.D. admission in structural engineering, what I really loved to be. I learned a lot form you and fortunately got the chance to learn more in the future.

Especial thanks to my committee members, Dr. Loferski and Dr. Moen for their contributions to this project and for all helps and advises that they provided. You guys are awesome! Dr. Moen, we will have fun time in my Ph.d. I promise! 
Justin Morris, my first American friend, thanks for your encouragements and helps, I learned a lot from you man. I never forget first moment I met you that you shake my hand strongly and told me; "By the way, I'm Justin".

Benjamin Richardson and Khris Beagley, talking and spending time with you guys was always fun! Thank you guys to always being good friends. Also thanks to other graduate student in our loft; Elham, Edgar, Oxana, Mellisa, and others to provide such a friendly academic community.

Last but not least, I would like to express my great thanks to the Brooks's employees, Debbie Garnand, Rick Caudill, David Jones, and especially Angela Riegel for all your helps and assistances. God bless you! 


\section{Table of Contents}

\section{Abstract}

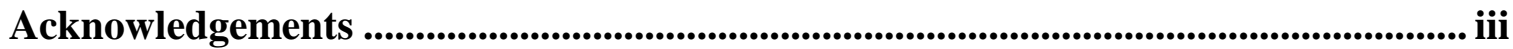

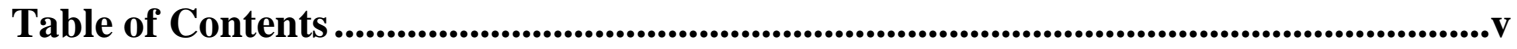

List of Figures..................................................................................................................................... viii

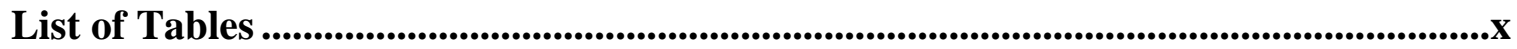

Chapter 1: Introduction .......................................................................................................................1

1.1. Goals and Objectives ..............................................................................

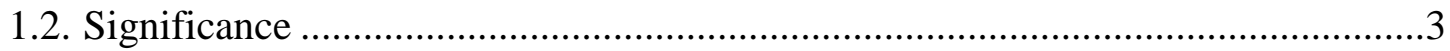

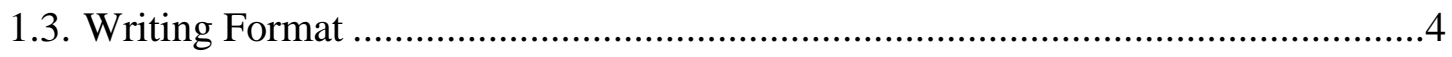

Chapter 2: Paper One: Rotational Stiffness of Wood Truss Joints in Lateral and Diagonal Bracing and Truss-Wall Connections.......................................................................5

2.1. Literature Review ..................................................................................

2.1.1. Behavior of Structural Connections ......................................................

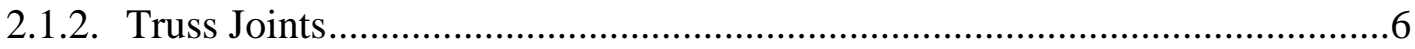

2.1.3. Lateral Load Truss Testing ................................................................ 8

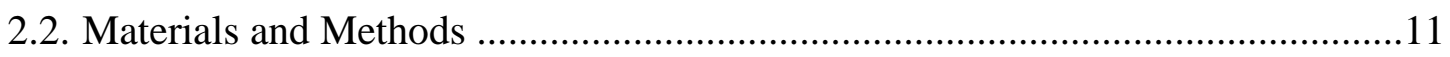

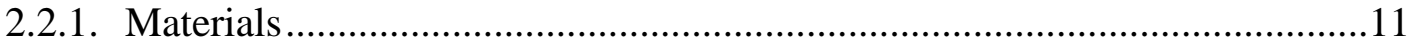

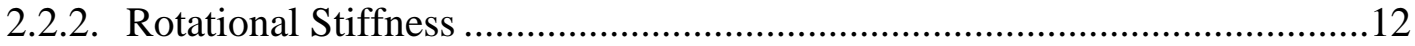

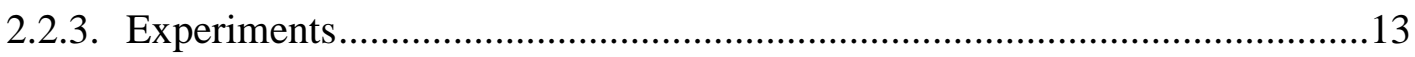

2.2.3.1. Rotational Stiffness of the Lateral Bracing........................................13

2.2.3.2. Rotational Stiffness of the Diagonal Bracing ....................................15

2.2.3.3. Rotational Stiffness of the Truss-Wall Connections...........................17

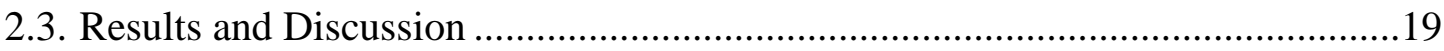

2.3.1. Lateral and Diagonal Bracing Tests .......................................................19

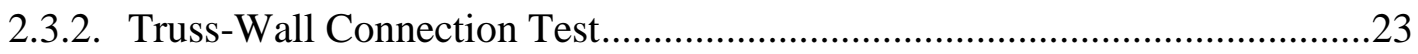




\section{Chapter 3: Paper Two: Analysis of Metal Plate Connected Wood Trusses Under} Out of Plane Loads Caused by Personal Fall Arrest System .....................28

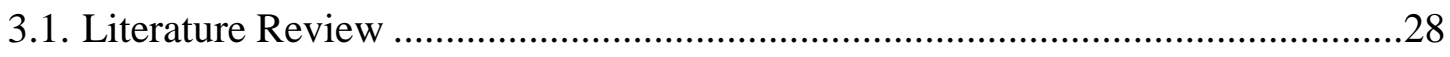

3.1.1. Structural Behavior of MPCWT Assemblies ............................................28

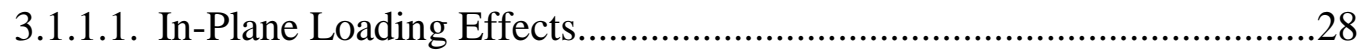

3.1.1.2. Out-of-Plane Loading Effects ...................................................... 31

3.1.1.2.1. Out-of-Plane Loads Caused by Personal Fall Arrest System ........32

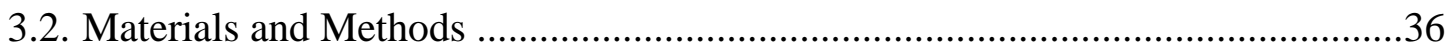

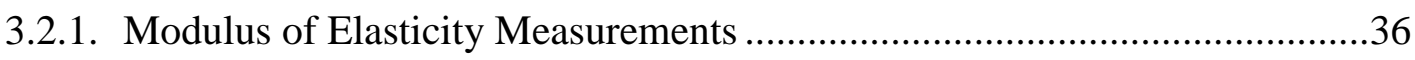

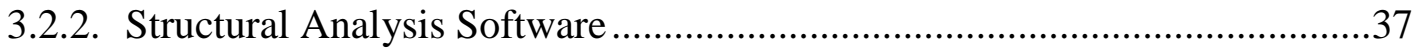

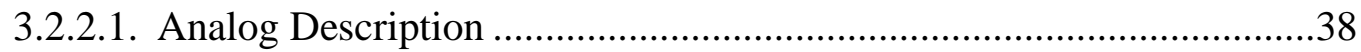

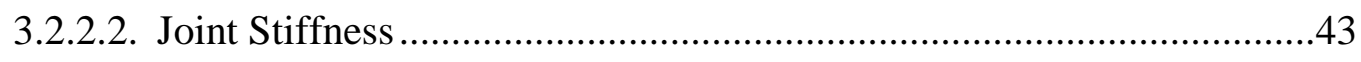

3.2.2.3. Model Load and Response ..........................................................43

3.2.3. Validation of the Model and Experiment .................................................44

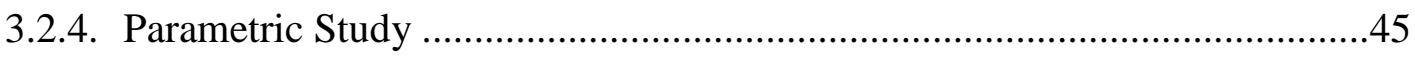

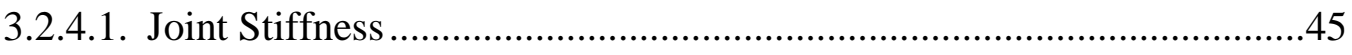

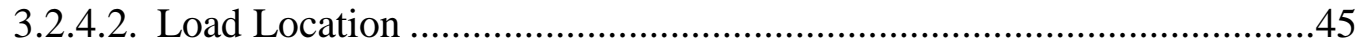

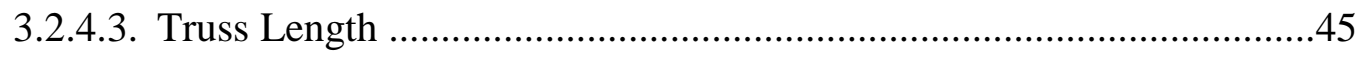

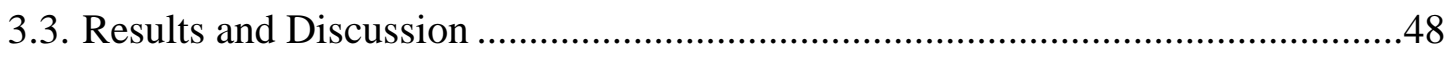

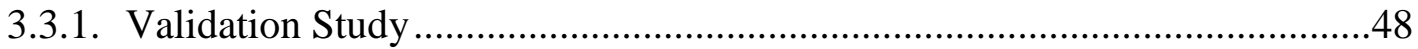

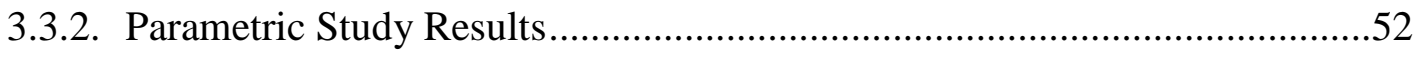

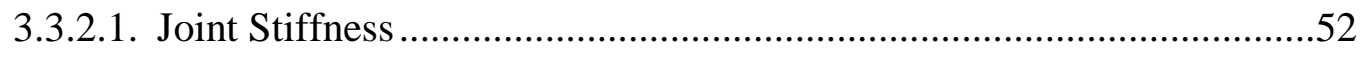

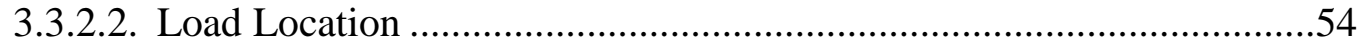

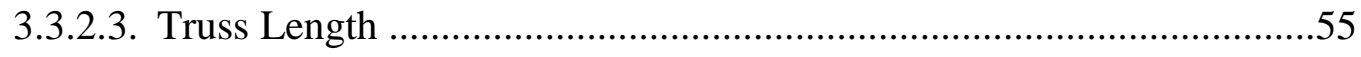

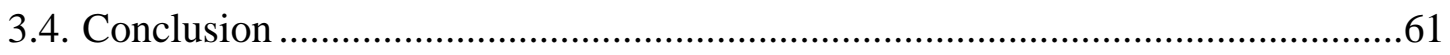




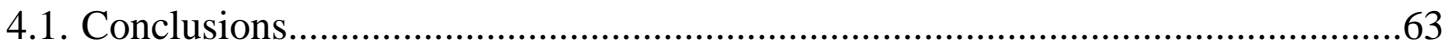

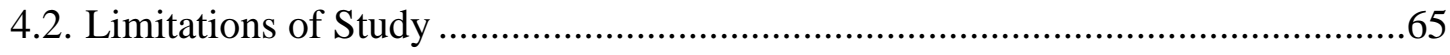

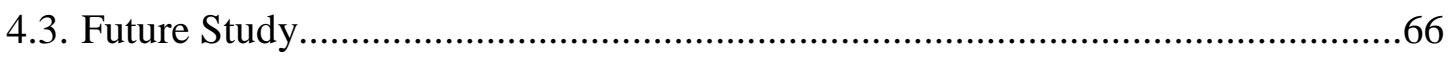

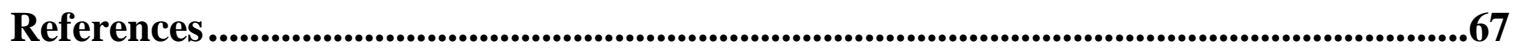

APPENDIX .....................................................................................................................................70

APPENDIX A: Rotational Stiffness of Lateral Bracing Test Data ...............................70

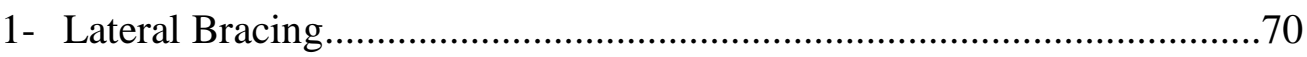

2- Diagonal Bracing .....................................................................................

APPENDIX B: Rotational Stiffness of Truss-Wall Connection Test Data ...................72

1- Hurricane Clip In Tension ........................................................................72

2- Hurricane Clip In Compression ................................................................73

APPENDIX C: Moisture Content and Specific Gravity Test Data ...............................74 


\section{List of Figures}

Chapter 2: $\quad$ Paper 1 .......................................................................................................................5

Figure 2-1: $\quad$ Morris (2013) MPCWT assembly ..........................................................10

Figure 2-2: $\quad$ Rotation of (a) truss-wall connection and (b) truss assembly (Morris 2013)

Figure 2-3: Fixed end cantilever beam ……………….......................................12

Figure 2-4: $\quad$ Rotational stiffness test of the lateral bracing (a) schematic and (b) experimental test ...................................................................................14

Figure 2-5: Rotational stiffness test of the diagonal bracing (a) schematic and (b) experimental test .....................................................................................16

Figure 2-6: Rotational stiffness test of the truss-wall connections when in (a) compression and (b) tension ...............................................................18

Figure 2-7: $\quad$ Moment-rotation diagram of lateral bracing ..............................................20

Figure 2-8: Moment-rotation diagram of diagonal bracing .........................................21

Figure 2-9: $\quad$ Failure modes of lateral truss bracing ........................................................22

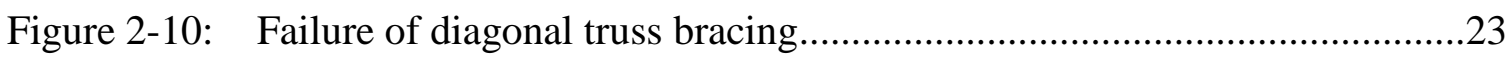

Figure 2-11: Moment-rotation diagrams of hurricane-clips test in compression side and tension side

Figure 2-12: Failure modes of truss-wall connections in (a) compression and (b) tension side. Clockwise rotation of torsion actuator is shown in the picture .........26

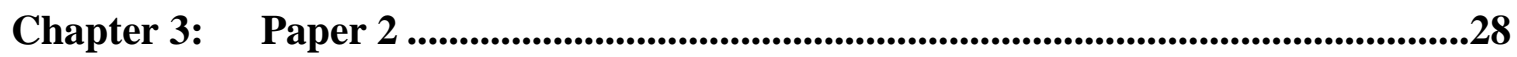

Figure 3-1: Five truss assembly showing wood bracing between top chords (Morris 2013)

Figure 3-2: Structural analog of five truss assembly constructed in VA and experimental set up as conducted by Morris (2013); (a) Morris "standard" model, (b) Morris "improved" model, and (c) Experimental set up of standard model 40

Figure 3-3: Location of simple and rigid connections in the truss assembly 43 
Figure 3-4: $\quad$ Four different truss lengths to be studied.........................................47

Figure 3-5: Members' axial forces in the standard model .......................................50

Figure 3-6: Members' axial forces in the improved model ......................................51

Figure 3-7: (a) Members' axial forces in the $20 \mathrm{ft}$. long truss ..................................58

Figure 3-7: (b) Members' axial forces in the $25 \mathrm{ft}$. long truss .................................59

Figure 3-7: (c) Members' axial forces in the $30 \mathrm{ft}$. long truss .................................60 


\section{List of Tables}

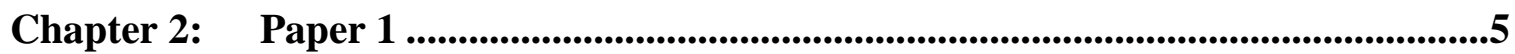

Table 2-1: $\quad$ Rotational stiffness $K$, values of truss bracing ....................................19

Table 2-2: $\quad$ Rotational stiffness $K$, values of truss-wall connections .........................24

Chapter 3: $\quad$ Paper 2 ....................................................................................................................28

Table 3-1: $\quad$ Summary of maximum loads and deflection from Morris (2013) .............35

Table 3-2: $\quad$ MOE and material properties of SP and SPF........................................37

Table 3-3: $\quad$ Analog members with connection assumption types .............................42

Table 3-4: $\quad$ Validation study results; comparison of experimental and modeling displacement values at the peak of the first truss.....................................48

Table 3-5: $\quad$ Axial forces in the right side lateral brace (lbs.) ...................................49

Table 3-6: Joint stiffness parametric study results ..............................................53

Table 3-7: $\quad$ Load location parametric study results ...........................................55

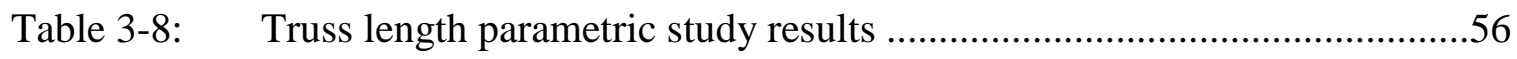

Table 3-9: $\quad$ Maximum axial forces in the right lateral brace (lbs.) .............................57 


\subsection{Introduction}

Falls from elevation are one of the primary causes of injuries and deaths on construction sites (Ellis 2011). Work at elevations such as roofs and scaffolding is a main concern of construction safety professionals because of the potential for fall hazards. Of all fatal occupational injuries, 15\% are related to slips, trips and falls (STF) (US Department of Labor 2012). After roadway incidents, STF are the second greatest cause of fatal injuries (US Department of Labor 2012).

The Occupational Safety and Health Administration (OSHA) specifies safety requirements for workers who are working in construction industry including residential and commercial. The Campaign to Prevent Falls in Construction is a two year campaign sponsored by the OSHA directorate in construction in collaboration with government, academic and industry to emphasize fall prevention during residential construction (www.stopconstructionfalls.com) (CPWR 2014). According to the campaign website each year more than 200 construction workers are killed and over 10,000 are seriously injured by falls (CPWR 2014). OSHA requires that workers in residential construction at 6 feet $(1.8 \mathrm{~m})$ or greater above a lower level to be protected by safety equipment such as safety nets, guardrail systems or personal fall arrest systems or a combination thereof (OSHA 2010a).

Workers in residential construction can use personal fall arrest systems as safety equipment to comply with OSHA guidelines. The OSHA specifies the minimum requirement and capacity of anchor attached to a structure in OSHA 29 CFR 1926.502(d)(15) (OSHA 2011b), stating:

1926.502(d)(15) Anchorages used for attachment of personal fall arrest equipment shall be independent of any anchorage being used to support or suspend platforms and capable of supporting at least 5,000 lbs. $(22.2 \mathrm{kN})$ per employee attached, or shall be designed, installed, and used as follows: 
1926.502(d)(15)(i) as part of a complete personal fall arrest system which maintains a safety factor of at least two; and

1926.502(d)(15)(ii) under the supervision of a qualified person.

The safety factor at least two is referring to the maximum arresting force of a worker when wearing a full body harness, which is $900 \mathrm{lbs}$ (Koch et al. 2014). Therefore, reaching a safety factor of two is possible when the anchor can carry $1800 \mathrm{lbs}$. (Hindman et al. 2013).

A personal fall arrest system anchor can be attached to a fixed structural element such as a group of roof trusses (Ellis 2011). Metal plate connected wood trusses (MPCWT) are widely used in residential construction, so these trusses are often seen as a convenient place to attach a safety anchor. Trusses are designed to carry service load such as roof dead and live loads as well as snow loads, but trusses are not designed to carry out-of-plane rotational or impact load (Kassimali 2010). The attached fall arrest system (FAS) can cause out-of-plane loading in the horizontal direction on trusses in the event of a fall. Analysis of these trusses during construction and under loads applied due to fall arrest system (FAS) anchors is needed to ensure the strength of the truss assembly.

Previous research has investigated the strength of fall arrest systems attached to MPCWTs (Koch et al. 2014, Morris 2013). Different anchors attached to single and multiple braced trusses under horizontal out-of-plane loads were studied as well as different bracing systems. The loading was a horizontal force applied perpendicular to the truss plane. Because of experimental limitations, only a limited number of truss configurations were investigated. In both studies, rotation of trusses and failure of truss bracing joints and end supports under FAS applied loads were reported (Koch et al. 2014, Morris 2013).

Considering the observed experimental limitations of laboratory space and material expense, there is a need to analyze larger span trusses under FAS loads with different bracing configurations. Modeling of truss assemblies under out-of-plane loads such as wind and FAS loads 
is a good option to alleviate experimental difficulties with appropriate validation. Modeling also allows the parametric study of MPCWT variables that affect truss assembly behavior under outof-plane loads.

\subsection{Goals and Objectives}

The goal of this research is to construct and validate a structural analog of MPCWT assemblies under out-of-plane fall arrest loads considering the rotational stiffness of elements in MPCWT assemblies. The objectives of this research are specified in order as follows:

(1) Measure the rotational stiffness of truss bracing (lateral and diagonal) and truss-wall connections for use in the structural component model.

(2) Model and validate the MPCWT truss assembly with test results from Morris (2013) using structural analysis software and joint stiffness values from Objective (1).

(3) Using the validated model from Objective (2), conduct a parametric study considering truss length, FAS location and bracing stiffness considering the effects upon a MPCWT assembly.

\subsection{Significance}

Fulfillment of these research objectives will provide tools to benefit safety and design professionals. Validation of the MPCWT model from experimental testing (Morris 2013) will demonstrate the use of structural analysis software to predict out-of-plane loading of MPCWT. The role of truss-wall stiffness and bracing stiffness in model validation will be studied. These results will provide knowledge for safety professionals, FAS designers and truss manufacturers to predict the structural performance of MPCWT assemblies under out-of-plane loads such as wind and FAS loads. Validated structural analog will allow modeling and study of more complex truss configurations and roof situations. 


\subsection{Writing Format}

The current thesis is written as a series of papers rather than conventional thesis format.

For this purpose, two papers are outlined as the following chapters. The papers are written in a form to be submitted to the ASCE Journal of Structural Engineering. Paper 1 describes Objective (1), while Paper 2 describes Objectives (2) and (3). 


\subsection{Paper One: Rotational Stiffness of Wood Truss Joints in Lateral and Diagonal Bracing and Truss-Wall Connections}

\subsection{Literature Review}

\subsubsection{Behavior of Structural Connections}

Behavior of mechanical joints in timber structures have been studied by Kanerva et al. (2004). Traditionally, joints have been assumed to be either rigid or hinged, although the real behavior of joints is usually somewhere in between, known as semi-rigid behavior (Kanerva et al. 2004). Semi-rigid behavior can be modeled using either linear elastic or non-linear models to accurately evaluate the behavior of the structure. Among various models presented for momentrotation behavior of joints, the linear elastic theory is applicable to service limit states for the majority of structures. However, linear elastic theory is not as accurate as nonlinear models to predict ultimate loads, since local stress peaks are overestimated after material yielding using the linear elastic theory (Kanerva et al. 2004).

Zaharia and Dubina (2006) studied the stiffness of bolted cold-formed steel truss joints in the design load ranges. Joint stiffness in design was considered because of changes in AISI Cold Form Steel Truss Design (AISI 2001). Previously truss joints were assumed as pinned connections. Three experimental steps were followed, including (1) tests on T-joint specimens, (2) tests on single lap joints, and (3) tests on the truss structure, as well as computational models for rotational stiffness of truss joints (Zaharia and Dubina, 2006). Rotational stiffness of truss joints tested in steps (1) and (2) used a computational formula for model incorporation. Good agreement between experimental and computational models was found. The behavior of a single truss was not only influenced by rotational stiffness, but also by the axial stiffness of joints in the web member directions, although axial effects were smaller than rotational ones (Zaharia and Dubina 2006). 


\subsubsection{Truss Joints}

Connections in trusses are the locations that transfer axial forces between truss elements, and from truss members to the support elements. In structural analysis, truss connections are known as nodes which are important locations to ensure integrity of the truss assembly (Kassimali 2010). Gupta et al. (1992) investigated metal plated connected wood trusses (MPCWT) with semirigid joints using matrix structural analysis. Some modifications were applied to conventional cases in order to derive element stiffness matrix and fixed end forces of members with one or both ends acted as semi-rigid connections. Three different joint assumptions were analyzed, namely; pin, rigid, and semi-rigid joints. These joint assumptions has notable influence on amount of deflection. Joints with semi-rigid behavior deflected $34 \%$ less than pinned assumed joints and experienced $13 \%$ less moment compared the rigid joints. Actual prediction of truss behavior and more accurate member forces can be obtained if semi-rigid joints behavior was considered (Gupta et al. 1992).

Hussein (2000) conducted a parametric study on the instability problems of metal plate connected (MPC) joints in light frame trusses. Hussein (2000) used a database including more than 350 advanced computer simulations as well as experimental results obtained by previous researchers. Parameters of interest included; size of gaps, shear length, failure modes, progressive disintegration of joints and some other important parameters. Results showed that 'chord shear' dominates the buckling of MPC joints and the 'shear length' effect on the joint buckling is greater than 'size of gaps' effect. Moreover, smaller unbraced lengths and larger plate gauges improved the buckling behavior. Good agreement was found between analytical results of Hussein (2000) research and the experimental work of other researchers as well as classic buckling theory (Hussein 2000). 
Stehn and Borjes (2004) investigated the influence of nail ductility on the load capacity of a timber truss structure within the service load range. To find the effect of different shapes of the nail load-displacement curve on the load-carrying capacity of the truss, finite element and experimental analyses were performed. Results showed that the true elastic-plastic behavior of the nails should be considered to find the load-capacity of the truss structure rather than using linear elastic nail properties (Stehn and Borjes 2004).

Silih et al. (2005) studied the optimization of metal-plate-connected plane timber trusses with special emphasis on joint flexibility. Non-linear programming methods were used to optimize truss models. Variables such as truss configuration, span/depth ratio, number and type of diagonal and vertical members and type of joint connections, which may affect truss behavior were simultaneously taken into account in a single mathematical model. In the optimized model, joint flexibility increased maximum deflection by 10 or $15 \%$ on the timber truss, however the influence in the final results was less if the ultimate limit state criteria were used (Silih et al. 2005).

In a similar study, the shape and discrete sizing optimization of timber trusses with the consideration of joint flexibility was investigated (Silih et al. 2010). The Mixed-Integer NonLinear Programming (MINLP) was used as optimization approach. Internal forces and deflections were calculated using finite element analysis. Joint flexibility had a significant effect on the results of the analysis. Deflections due to slip of the truss connections represented over $40 \%$ of the total deflections (Silih et al. 2010).

An innovative end-support connection for wood trusses was proposed by Barbari et al. (2014). In the designing of the new connection same operating principles as conventional wood trusses, notably the resistance of wood to the shearing stresses in the grain direction, were considered. Increasing safety against shear loads that may cause failure was considered in the 
design procedure as well. Full-scale experimental test on a single truss was conducted to evaluate the behavior of the truss-wall connection as well as finite element modeling of the innovative connection. Results of finite element and experimental analysis were in good agreement. Using the innovative connection and testing, these trusses under the load at four times the design load, no failure was observed in the truss members and appropriate behavior of the new connection was confirmed (Barbari et al. 2014).

\subsubsection{Lateral Load Truss Testing}

DeRenzis et al. (2012) tested nine full size roof systems with various heights of heels and heel details in order to measure the lateral performance of the roof-to-wall interface. The objective of this research was to benchmark the performance of traditional roof truss systems and improve roof-to-wall connections optimized for performance and constructability as well as evaluation of these trusses for energy codes. High-heel truss performance under lateral loads was investigated in the paper as well. Trusses with the span of $24 \mathrm{ft}$, spaced 24 in o.c. were fabricated with No.2 southern pine lumber. Lateral and uplift loads was applied to the assembly using permanent truss bracing attached at mid-height of the center vertical web member of each truss. All trusses were connected to the top plate of the supporting walls using manufactured H2.5T hurricane clips (DeRenzis et al. 2012).

High-heel truss sheathed with oriented strand board (OSB) yielded similar performance to that of the unblocked, low-heel trusses currently allowed by the IRC. High-heel trusses braced with OSB sheathing and a reinforced ceiling diaphragm had the greatest peak load among all configurations tested. Initial stiffness of high-heel trusses braced with OSB sheathing measured at roof peak of specimen was the greatest among the configurations tested. Trusses with OSB sheathing were superior for use in high-wind regions since the performance in strength and 
stiffness was superior to trusses with solid, intermittent blocking. Additionally, buckling and rotation of hurricane clips caused rotation of the whole truss assembly (DeRenzis et al. 2012).

Koch et al. (2014) tested a single monoslope queenpost wood trusses conventional in residential construction under horizontal out-of-plane load. Brittle failure of the bottom chord and ductile failure of the truss-wall connection were reported. Truss failures were related to the trusswall connection with rotation of the truss about the horizontal axis. The rotational stiffness of the truss-wall connection was considered an influential factor for use in the future studies of trusses under lateral loads. Experimental evaluation of the rotational stiffness of these elements will use testing methods that represent the loads experienced by the lateral loading of the truss assembly. (Koch et al. 2014)

Morris (2013) studied roof truss assemblies with span of $13 \mathrm{ft}$. composed of five trusses with different bracing configurations under out-of-plane loading caused by FAS as shown in Figure 2-1. Three different types of bracing including wood in-between bracing, wood on-top bracing and MiTek as the steel braces were used. Out-of-plane horizontal load was applied to the structure to simulate loads caused by personal fall arrest system anchors.

Bracing comparisons showed that 'in-between' wood bracing is the most suitable form of bracing since greatest ultimate loads in the assembly was recorded in this test. In addition, woodin-between bracing was not cause of failure in any of the tests. On the opposite side, 'on-top bracing' did not perform satisfactory, and the bracing was the source of failure in the tests with nails withdrawal from the top of the trusses, therefore on-top bracing could not provide enough support for the structure under applied lateral load. However, working with engineered steel braces was convenient in case of installation and attachment, but the recorded maximum load in the 
assembly was less than other assembly bracing types testing and failure of the steel braces were observed in the tests (Morris 2013).

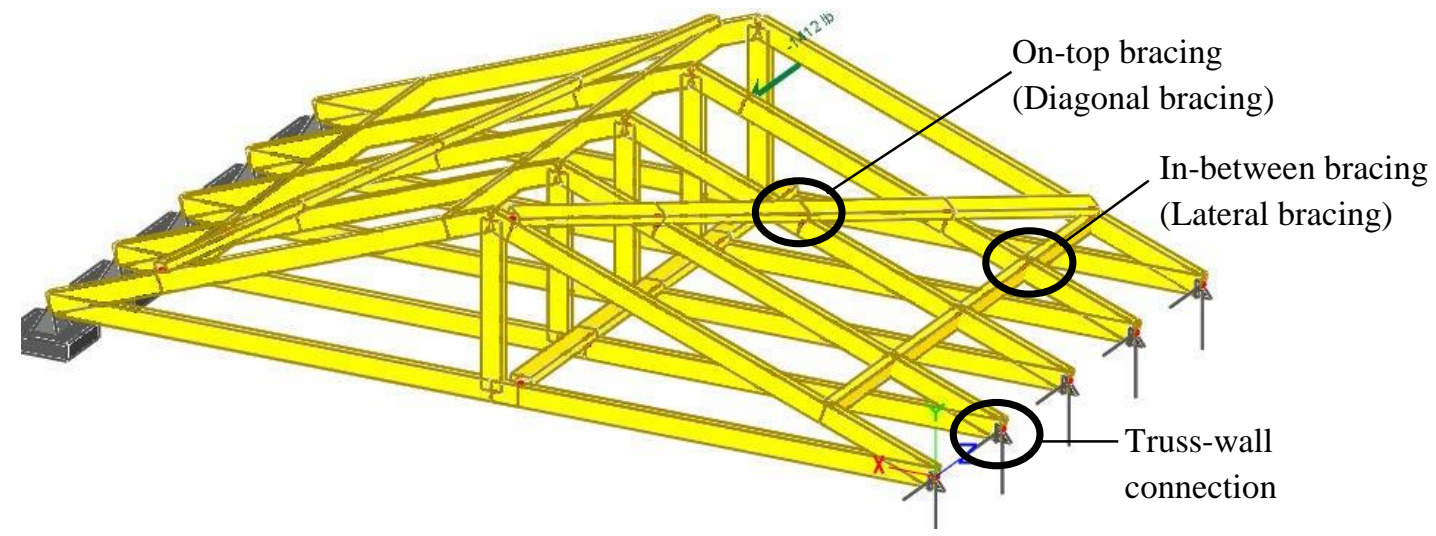

Figure 2-1- Morris (2013) MPCWT assembly

Morris (2013) also noted rotation of truss assemblies at the truss-wall connections (Figure 2-2 (a) and (b)). As the lateral load was applied to the truss assembly, the bracing elements experienced a bending moment causing a prying action of the nailed connection. The truss-wall connection experienced torsion of the bottom chord (Morris 2013).

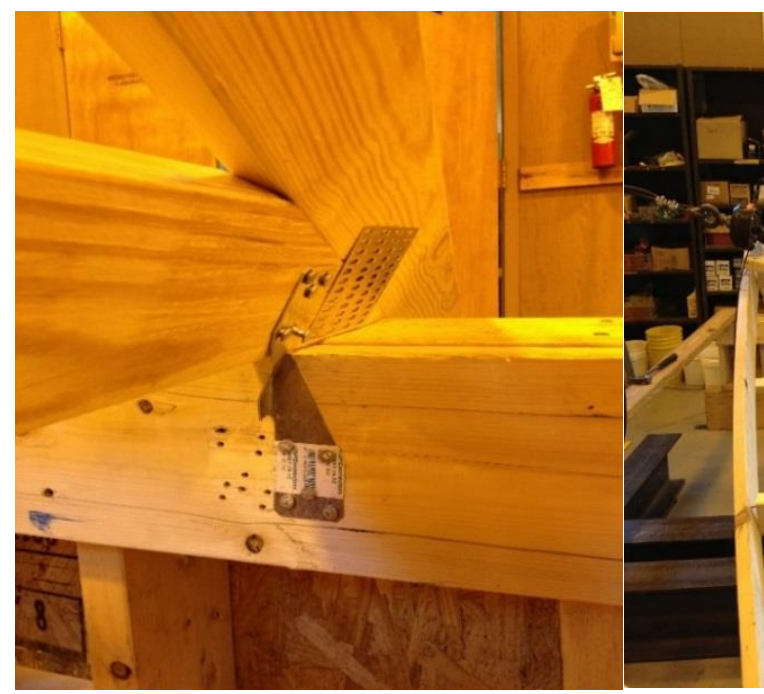

(a)

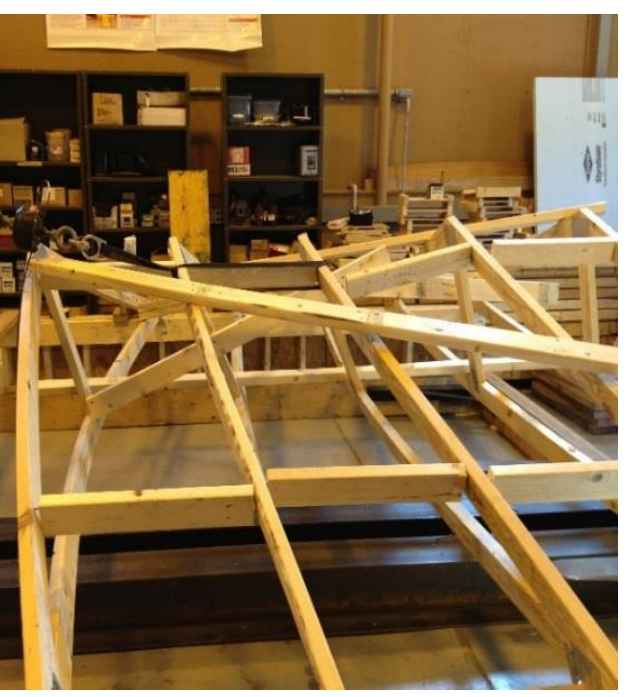

(b)

Figure 2-2- Rotation of (a) truss-wall connection and (b) truss assembly (Morris 2013) 
Rotation of trusses in the truss-wall connections and failure of truss bracing were observed and was the source of collapse in the experimental test on MPCWT assemblies conducted by DeRenzis et al. (2012), Morris (2013) and Koch et al. (2014). To analyze structures in service limit states, linear elastic theory can provide good estimation for structures behavior as well (Kanerva et al. 2004). Since joint stiffness had a significant effect on the results of the analysis (Silih et al. 2010), therefore, rotational stiffness of truss bracing and truss-wall connections in the MPCWT assemblies require further study to examine the effect of rotational stiffness on the deflection and failure of truss assemblies loaded out-of-plane.

The goal of this paper was to measure rotational stiffness of lateral and diagonal bracing as well as truss end supports in MPCWT assemblies in order to provide data for further modeling of truss assemblies when semi-rigid behavior of joints are considered. Experimental results can be used in structural analysis software when modeling truss assemblies considering deformation of the trusses.

\subsection{Materials and Methods}

\subsubsection{Materials}

This section describes the materials used to conduct the rotational stiffness testing of braces and truss-wall connections. All wood representing truss elements was No. 2 southern pine $2 \times 4$ (SP). All bracing materials used were No. 2 spruce pine fir $2 \times 4$ (SPF). All lumber was equilibrated in the Engineering Lab for three weeks before testing under uncontrolled indoor environmental conditions. After testing was conducted, specific gravity by displacement (ASTM D2395 method A) and oven-dry moisture content (ASTM D4442) were measured by cutting samples from specimens. The average values of moisture content and specific gravity of SP members were 
measured to be $7.35 \%$ and 0.48 , respectively, with COV of $5 \%$ for MC and $10 \%$ for specific gravity, respectively. The average values of moisture content and specific gravity of SPF members were also measured to be $7.54 \%$ and 0.45 , respectively with $\mathrm{COV}$ of $18 \%$ for $\mathrm{MC}$ and $9 \%$ for specific gravity. The NDS values of specific gravity for SP and SPF are 0.55 and 0.42 , respectively, which comparing to calculated values here are $14 \%$ and $7 \%$ greater.

\subsubsection{Rotational Stiffness}

Stiffness is defined as the rigidity of an object or the resistance against deformation under an applied load (Kanerva et al. 2004). Rotational stiffness depends on the angular rotation of the member as a function of an applied load. Joints in structures may be subject to rotational stiffness depending on structural function. The following equation was used to measure rotational stiffness of a joint. The equation assumes linear elastic theory is applicable for the majority of structures in service limit states as previously noted by Kanerva et al. (2004). Rotational stiffness $K$, is defined in Equation 2-1 and its components are shown in Figure 2-3.

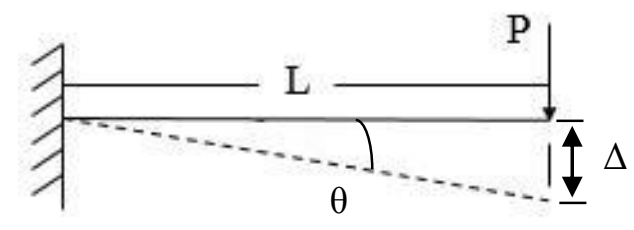

Figure 2-3- Fixed end cantilever beam

$$
K=\frac{M}{\theta}=\frac{P L}{\theta}
$$

where, $M$ is the moment at the joint, $\theta$ is the rotation angle of the joint (degree), and $L$ is the length of the moment arm.

Components contributing to the total stiffness of the joints include shear at joint, rotational stiffness of joint, and bending of beam. Calculations of bending deflection for the cantilever beam 
were conducted and showed that bending deflection in the cantilever beam was negligible. No significant shear force before bending was observed in the connection. Therefore, the only component that had significant effect on stiffness of the joints was rotational stiffness values that were calculated using Equation (2-1).

\subsubsection{Experiments}

\subsubsection{Rotational Stiffness of the Lateral Bracing}

Test method to find rotational stiffness values of lateral bracing (Figure 2-1), as primary bracing method used to connect trusses in Morris (2013) truss assembly is described in this section. The bracing connection consisted of a 22.5 inch long brace placed between two trusses and attached using two $16 \mathrm{~d}$ sinker nails at each end (0.161 inch diameter, 3.5 inch long). The brace was a No. $22 \times 4 \mathrm{SPF}$ and the support representing the truss element was a No. $22 \times 4$ SP member (Figure 2-1).

In the lateral bracing test, the experimental test examined a single bracing connection loaded perpendicular to the nails causing a prying action (Figure 2-4). The brace was assumed to rotate about the bottom edge of the truss support with no crushing. The SP support was fixed in place using two clamps.

The load was applied at the top of the brace 20 inch from the connection by an MTS universal testing machine, with displacement rate of $0.5 \mathrm{in} / \mathrm{min}$. The load was measured by 5000 lbs load cell integrated into the MTS machine with a displacement sensitivity of 0.001 inch, and an error less than $1 \%$ of the load. A maximum travel distance of 6 inch was used. The displacements at the loading location and at the support were measured continuously using a potentiometer with a range of $10 \mathrm{inch}$ and sensitivity of $0.001 \mathrm{inch}$. Displacement in the horizontal direction in the support was measured to ensure no transitional movement in the support as a result 
of the applied load and, thus no horizontal movement was recorded during the tests. Location of the potentiometers and therefore displacement measurement are also visible in Figure 2-4.

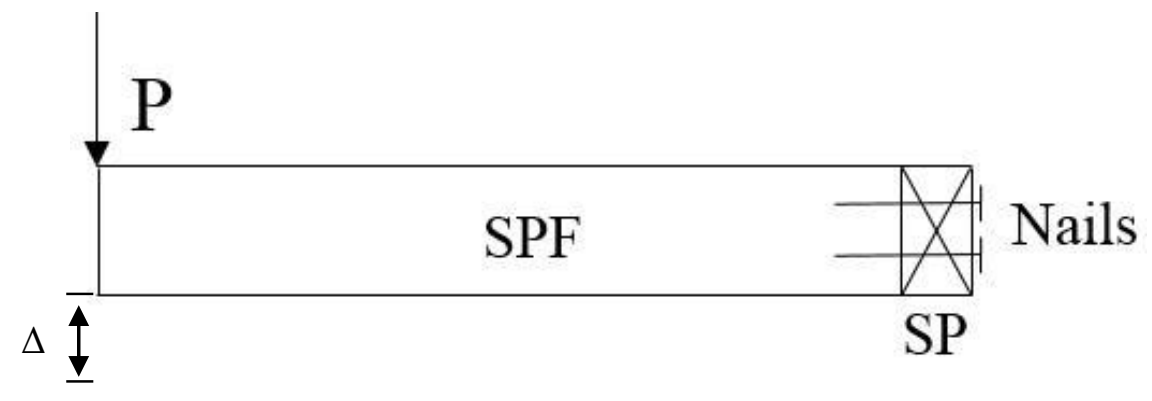

(a)

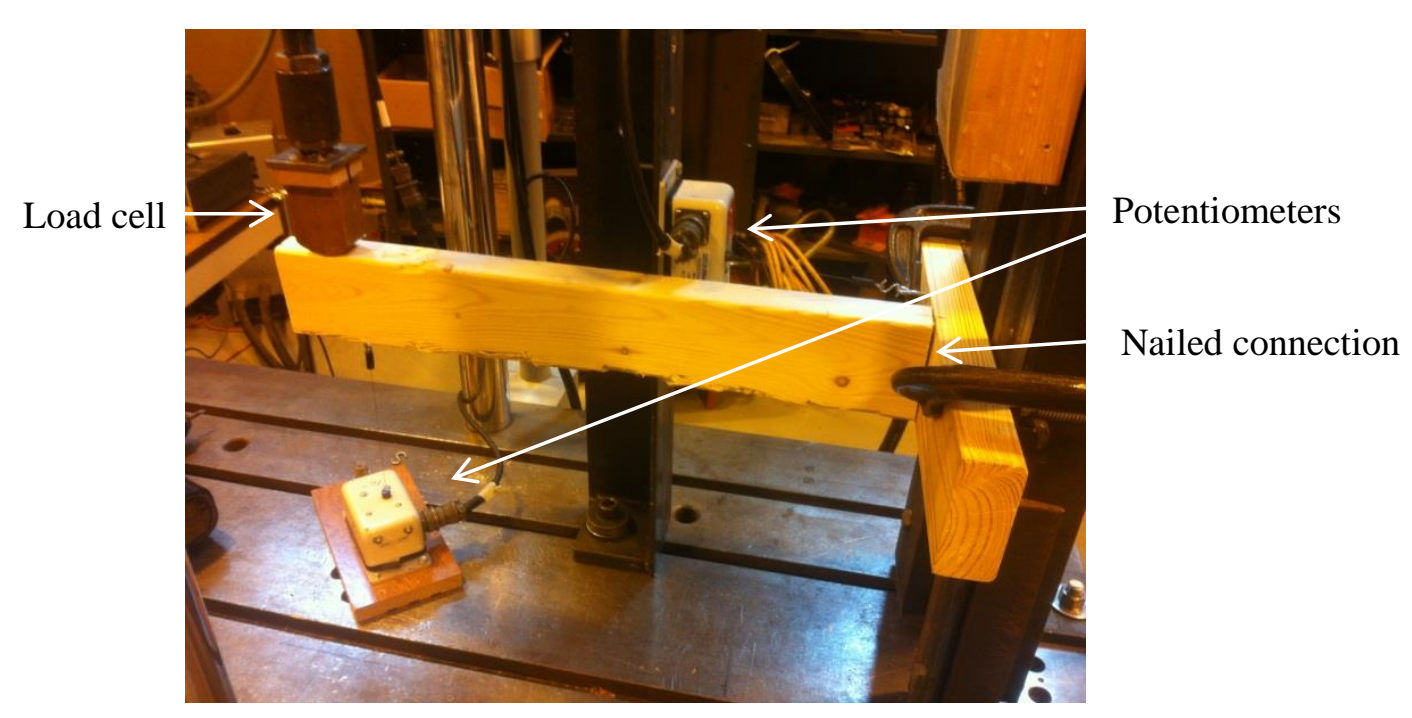

(b)

Figure 2-4- Rotational stiffness test of the lateral bracing (a) schematic and (b) experimental test

A total of 20 samples were tested to obtain the rotational stiffness of the truss lateral bracing joints. The moment was calculated as the load multiplied by the moment arm. The rotation angle $\theta$, was calculated using triangular geometry relations. In the lateral bracing test, the maximum load was recorded and then displacement at that load was measured. Then the moment, the degree of rotation and accordingly rotational stiffens of joints were calculated as well. The moment-rotation slope $(M / \theta)$ specified in Equation 2-1, was used to calculate rotational stiffness. 


\subsubsection{Rotational Stiffness of the Diagonal Bracing}

The test method to measure rotational stiffness values of diagonal bracing (Figure 2-1), as bracing method used to connect trusses diagonally in Morris (2013) truss assembly, is described in this section. The bracing connection consisted of a $10 \mathrm{ft}$. long brace placed on top of the trusses and attached using two $16 \mathrm{~d}$ sinker nails to the each truss top chord (0.161 inch diameter, 3.5 inch long). The brace was a No.2 $2 \times 4 \mathrm{SPF}$ and the support representing the truss element was a No.2 2×4 SP member (Figure 2-1).

In the diagonal braces test and for simplicity, the experimental test is examined one bracing connection loaded parallel to the nails causing a prying action (Figure 2-5). The brace was assumed to rotate about the top edge of the support plate with no significant crushing. The SP support was fixed in place using two mechanical fasteners.

The load was applied at the top of the brace 20 inch from the connection by an MTS universal testing machine, with displacement rate of $0.5 \mathrm{inch} / \mathrm{min}$. The load was measured by 5000 lbs. load cell integrated into the MTS machine with a displacement sensitivity of 0.001 inch, and an error less than $1 \%$ of the load. A maximum travel distance of 6 in was used. The displacements at the loading location and at the support were measured continuously using a potentiometer with a range of 10 inch and sensitivity of 0.001 inch. Displacement in the support was measured to ensure no transitional movement in the support as a result of the applied load and, thus no horizontal movement was recorded during the tests. Location of the potentiometers and therefore displacement measurement are shown in Figure 2-5. 


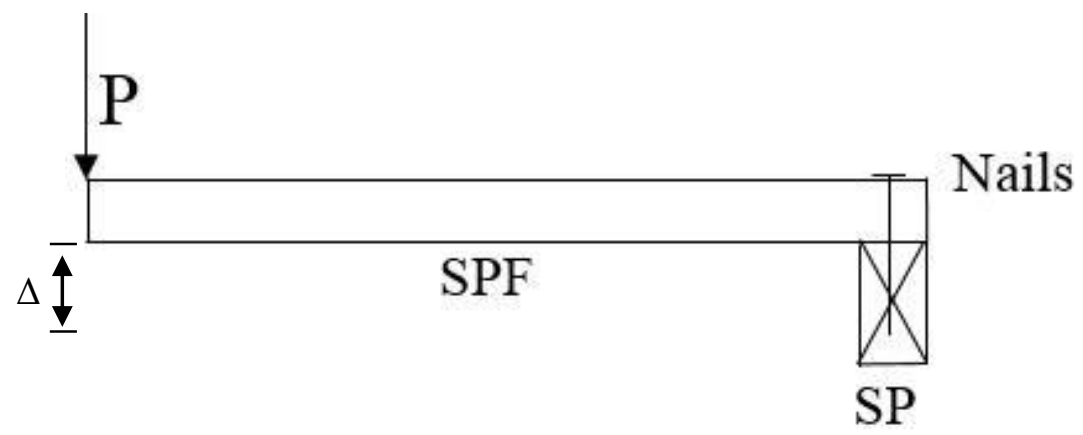

(a)

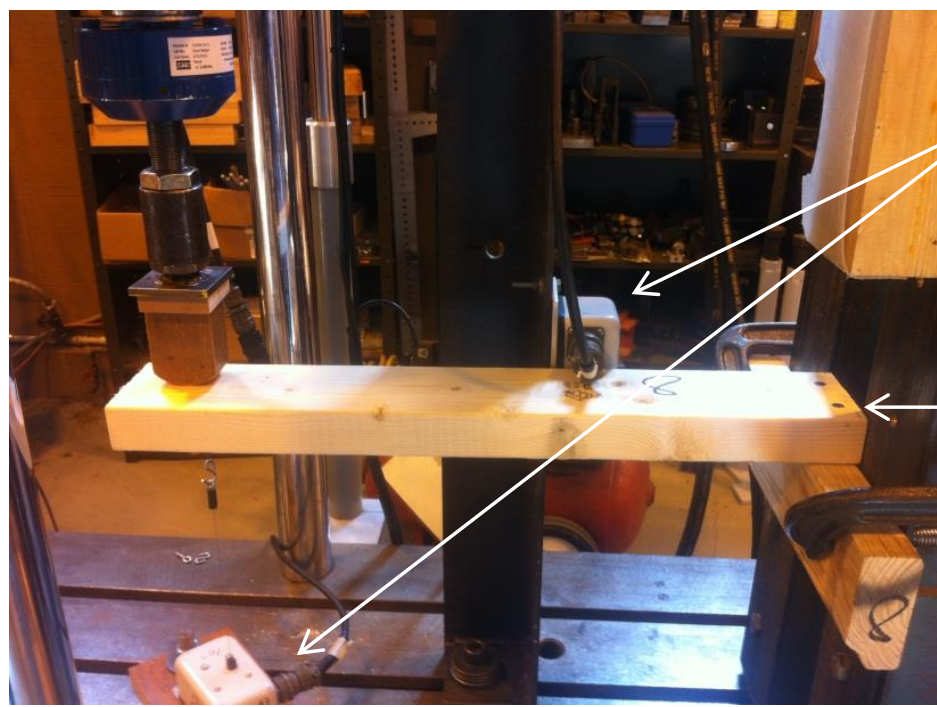

Potentiometers

Nailed connection

(b)

Figure 2-5- Rotational stiffness test of the diagonal bracing (a) schematic and (b) experimental test

The brace member as the load applied to that is SPF in the Figure 2-5, and the truss member is the fixed support is SP. A total of 20 samples were tested to obtain the rotational stiffness of the truss lateral bracing joints. The moment was calculated as the load multiplied by the moment arm. The rotation angle $\theta$, was calculated using triangular geometry relations. In the diagonal bracing test, the maximum load was recorded and then displacement at that load was measured. Then the moment, the degree of rotation and accordingly rotational stiffens of joints were calculated as well. 
The moment-rotation slope $(M / \theta)$ specified in Equation 2-1, was used to calculate rotational stiffness.

\subsubsection{Rotational Stiffness of the Truss-Wall Connections}

The rotational stiffness of the truss end supports (hurricane ties) used by Morris (2013) were measured. A No. $22 \times 4$ SP lumber, 5 feet long represented the truss bottom chord and was attached to one No. $22 \times 4$ SPF using one hurricane clip (RT7A-TZ). The hurricane clips were attached to wood members using 10 N10 D5HDG nails (1.5 inch long and 0.148 inch diameter). Samples were constructed in the lab and then inserted to the test platform (Figure 2-6).

An MTS torsion actuator with a 50,000 inch-lbs. maximum capacity and 500 inch-lbs. sensitivity applied a torque with a speed of 2 degrees/min to the free end of the specimen (not connected by hurricane clip), as shown in Figure 2-6. The samples were under constant angular displacement until a maximum rotation of 30 degrees was reached. A total of 20 samples were measured to obtain the rotational stiffness of the truss-wall connections. The moment was measured in the location of the applied load. The rotation was monitored using Accustar II / DAS20 dual axis clinometer with accuracy of $20 \pm 0.01$ degrees. The moment and rotation angle were continuously measured throughout the test and the moment $M$, and rotation $\theta$, values were used in Equation (2-1) for rotational stiffness measurement. 


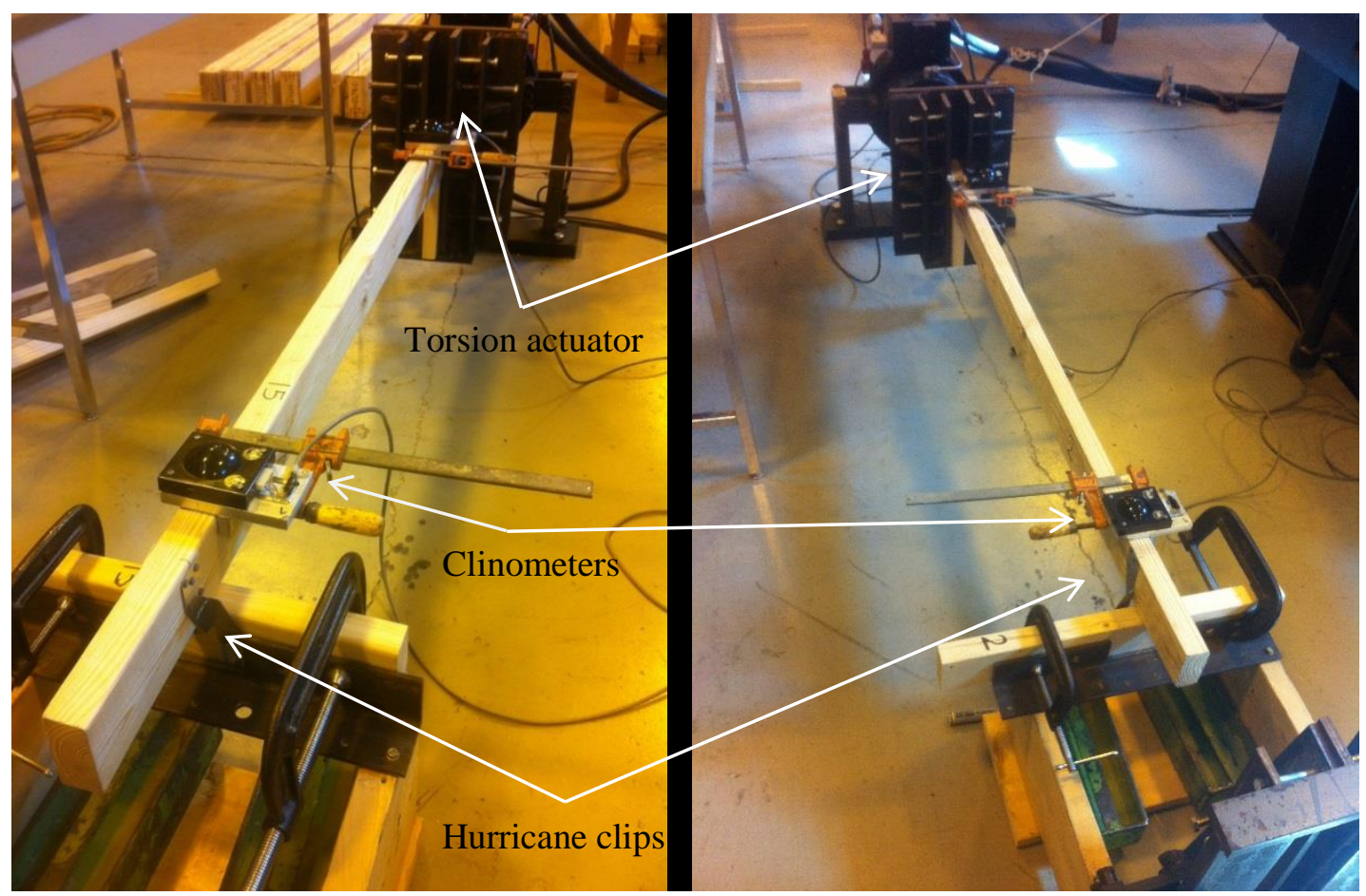

(a)

(b)

Figure 2-6- Rotational stiffness test of the truss-wall connections when in (a) compression and (b) tension

In the testing performed by Morris (2013), each truss was attached to the wall underneath by right-handed hurricane ties, therefore in the test hurricane ties experienced tension in one side and compression in another side. The direction of the hurricane tie placement affects the direction of load, either compression loading or tension loading. Therefore two different sets of 10 specimens with both methods of installation were tested. The torsion actuator can only rotate to the right direction, so in order to provide the loading condition for the compression and tension in the hurricane ties, the ties location were changed to the right and left side of $2 \times 4$ SPs (Figure 2-6). 


\subsection{Results and Discussion}

\subsubsection{Lateral and Diagonal Bracing Tests}

Rotational stiffness $K$, experimental test values of truss bracing are represented in Table 21. In two different types of bracing tested here, lateral bracing has greater rotational stiffness values. Average rotational stiffness values of lateral and diagonal bracing is significantly different since approximately 3 times difference was found between two $K$, values. Coefficient of variation $(\mathrm{COV})$ in lateral bracing test is less than the diagonal bracing. Fifty percent coefficient of variation for diagonal bracing is the results of the ratio of low standard deviation to the greater average stiffness values. The flexibility and large amount of deflection of nailed brace on the support under applied load in diagonal bracing test could be the reason for high COV observed here.

Table 2-1. Rotational stiffness $K$, values of truss bracing

\begin{tabular}{ccc|c}
\hline & $\begin{array}{c}K^{l} \\
(\text { lb.in/degree })\end{array}$ & COV & \multicolumn{1}{c}{$\begin{array}{c}\text { Percent of } \\
\text { difference }^{2}\end{array}$} \\
\hline Lateral bracing & $89.51 \pm 26.04$ & $29 \%$ & \multirow{2}{*}{$317 \%$} \\
\hline Diagonal bracing & $21.44 \pm 10.66$ & $50 \%$ & \\
\hline${ }^{1}$ Values are average \pm SD & & \\
${ }^{2} \%$ of difference $=\left(\mathrm{K}_{\text {lat }}-\mathrm{K}_{\text {diag }}\right) / \mathrm{K}_{\text {diag }}$ & & &
\end{tabular}

One of the moment-rotation diagrams of the lateral bracing test is shown in Figure 2-7. In this particular test, the maximum moment was 342 inch-lbs. and fluctuated downward to minimum value of 200 inch-lbs. until 0.15 radians rotation. The average moment for this portion was approximately 270 inch-lbs. The failure mode of lateral bracing was also the reason of this behavior since nails could tolerate certain amount of moment (342 inch-lbs.) and then bending and pull out procedure was start. The parallel horizontal position of the nails in lateral bracing may result in the greater stiffness values, since the lower nail bends less and slows the bending of the upper nail to provide increased resistance against the applied load. 


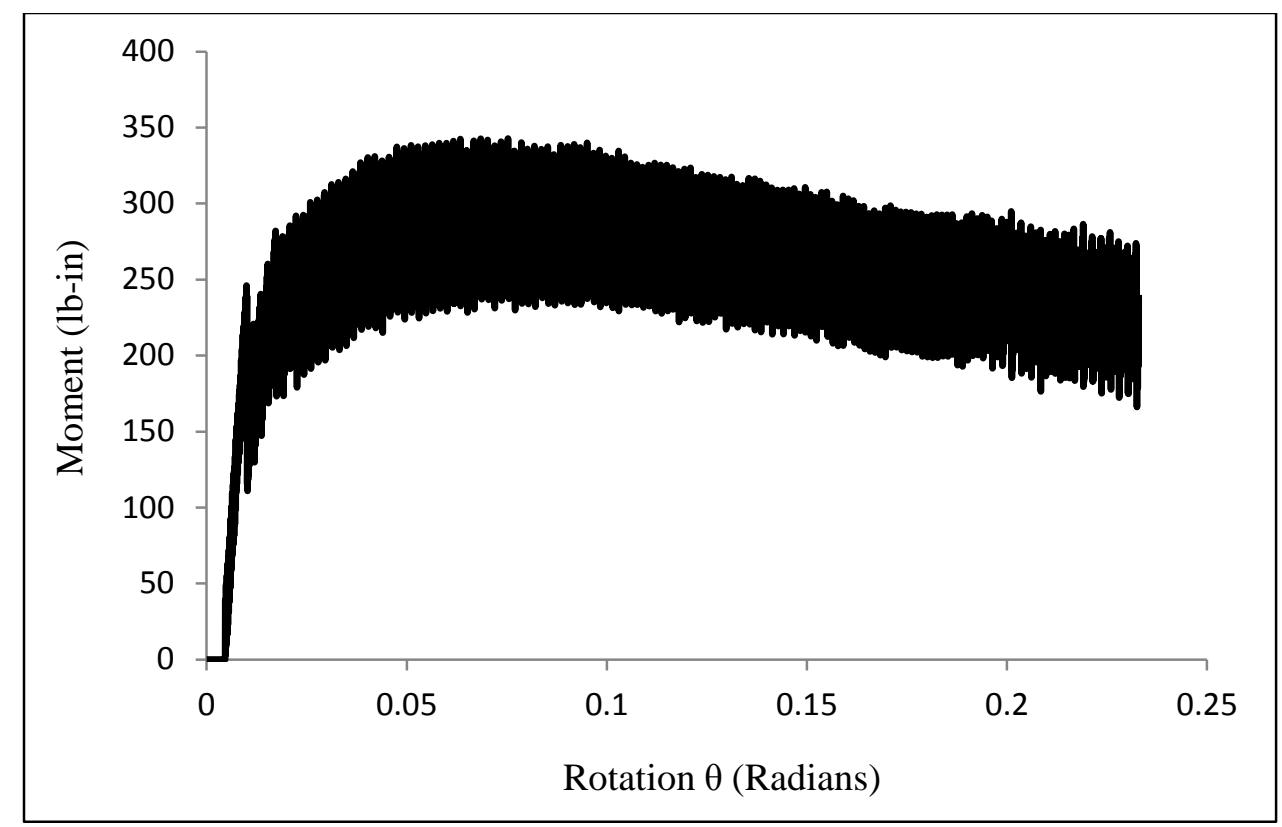

Figure 2-7- Moment-rotation diagram of lateral bracing

A moment-rotation diagram of a diagonal bracing test is shown in Figure 2-8. The maximum moment was 280 inch-lbs. and fluctuated downward to 107 inch-lbs. and kept same trend of fluctuation all the way to the end. The average moment for this portion was approximately 210 inch-lbs. The diagonal bracing configuration was also the reason of this moment-rotation behavior. Parallel vertical position of the nails in diagonal bracing test is in a manner that nails have same amount of contribution in resistance against applied load. Therefore, bending amount of two nail was almost same during the test and one could not help another to provide enough resistance. Therefore, after certain amount of moment and rotation (yield position of nails), moment was kept same to the end of the test as rotation degree increased (Figure 2-8). 


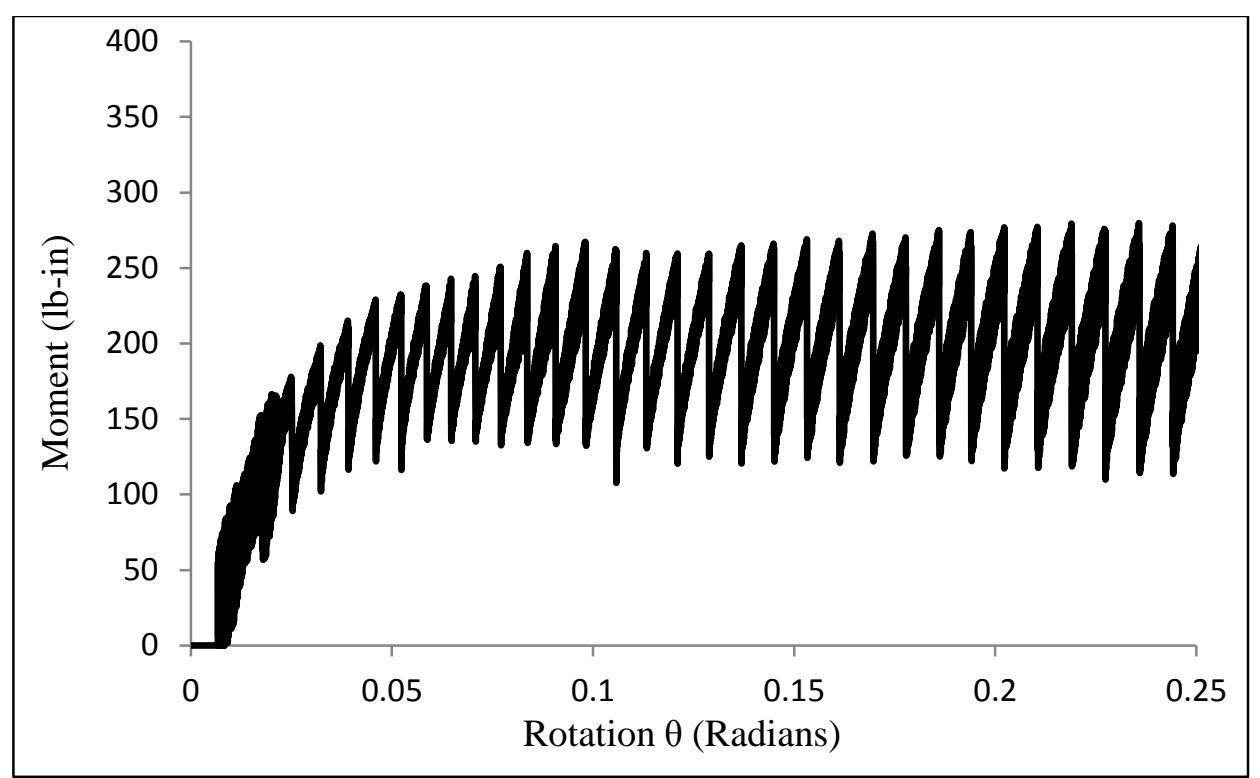

Figure 2-8- Moment-rotation diagram of diagonal bracing

As shown in the Figures 2-7 and 2-8, ultimate moment in the lateral bracing configuration was greater than diagonal bracing. The moment-rotation trend is also different in these two diagrams as well. In the diagonal bracing, the difference between the highest and lowest moment in diagram (173 inch-lbs.) was greater than lateral bracing (142 inch-lbs.). Also, in the diagonal bracing, the moment fluctuated more as rotation degree increased, and the upraise pattern is maintained, while in the lateral bracing, the moment is fluctuated less and began to decrease after approximately 0.1 radians. These variation in the data which is considerably high for diagonal bracing (Figure 2-8) may result from the small clearance between the two connected members. Considering the moment-rotation diagrams of both tests (Figures 2-7 and 2-8), lateral bracing had higher rotational stiffness values with less variation in the data. After careful observation of loaddisplacement diagrams, it was determined that the sensitivity of instrument and electrical noise are not the cause of this variable trend, since a $5000 \mathrm{lbs}$ load cell was used for this study.

Observed failure modes of the lateral and diagonal bracing types are shown in Figure 2-9 and 2-10, respectively. In the lateral bracing test as shown in Figure 2-9, as load applied to the 
free-end of SPF member as the brace, the wood pull out from the nails. As the brace separates, the nails begin to bend, where amount of bending and pull-out in the upper nail was greater than the lower one. Since the nails were attached to end-grain, there is little resistance to prevent the nail pull out, so the wood brace smoothly and easily moved as the load was applied. This can be the reason for greater values of calculated rotational stiffness, $K$ compared to the diagonal bracing test. As mentioned earlier, parallel nails in horizontal direction can be the reason of high rotational stiffness value in this test in comparison to diagonal bracing. Since the lower nail provided support for the upper nail and bended less than the upper one, the resistance against applied load was greater in this test.

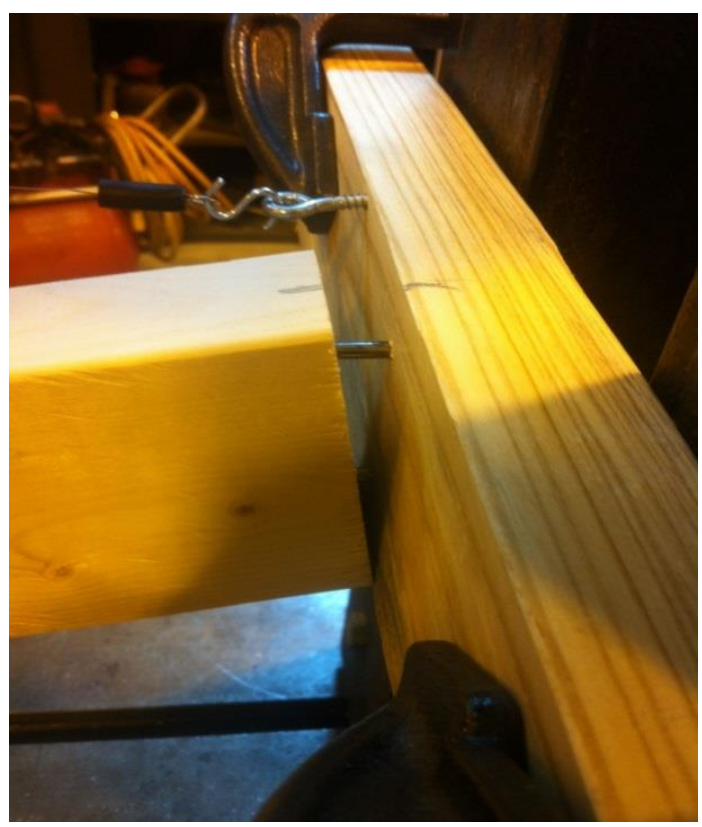

Figure 2-9- Failure mode of lateral truss bracing

A photograph of the failure of diagonal bracing specimen is shown in Figure 2-10. Similar procedure to the lateral bracing (pull out and bending) was observed in the diagonal bracing test. In this test, although the nails were not in end-grain, the gradual pulling out procedure in the bracing member was observed and also same amount of bending was observed in parallel vertical 
nails. However, the amount of bending was the same in both nails but overall nails bending was smaller than lateral bracing test. This may be the reason for lower values of calculated rotational stiffness compared to the lateral bracing values.

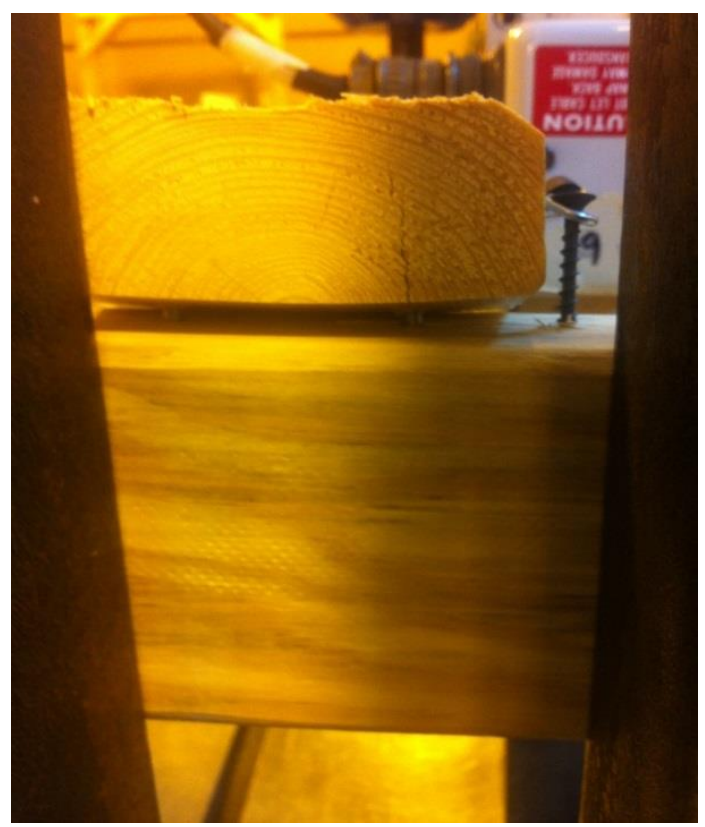

Figure 2-10- Failure of diagonal truss bracing

\subsubsection{Truss-Wall Connection Test}

Rotational stiffness values of truss-wall connection is given in Table 2-2. Rotational stiffness values are notably differ when the position of the hurricane clips was changed, in compression or tension side. When hurricane clips were loaded in tension, the greatest rotational stiffness values (100.54 inch-lbs/degree) were recorded. When hurricane clips were loaded in compression, average rotational stiffness that was recorded is 3.06 inch-lbs/degree that is the lowest among all tests and can be considered negligible. The difference between compression and tension tests is approximately 30 times which is significantly greater than lateral and diagonal bracing tests percent of difference. 
Table 2-2. Rotational stiffness $K$, values of truss-wall connections

\begin{tabular}{ccc|c}
\hline & $\begin{array}{c}K^{l} \\
(\mathrm{lb} . \mathrm{in} / \text { degree })\end{array}$ & COV & \multicolumn{1}{c}{$\begin{array}{c}\text { Percent of } \\
\text { difference }\end{array}$} \\
\hline End-supports (Tension) & $100.54 \pm 23.41$ & $23 \%$ & \multirow{2}{*}{$3185 \%$} \\
\hline End-supports (Compression) & $3.06 \pm 1.09$ & $36 \%$ & \\
\hline
\end{tabular}

${ }^{1}$ Values are average \pm SD

Moment-rotation diagrams of hurricane clips test is shown in Figure 2-11, in compression side and in tension side. As shown in this figure, when hurricane clip was in tension, the moments was significantly greater at the joint in smaller degrees of rotations, but once in compression the moment capacity of the connection is decreased and the degree of rotation to reach the maximum moment is increased. The ultimate moment in Figure 2-11 where the hurricane clip was in tension was 1600 inch-lbs. which in comparison with ultimate moment when hurricane clip was in compression side that is 58 inch-lbs., is a lot greater. This is the reason of high rotational stiffness values in truss-wall connections when attached in the tension side of the member.

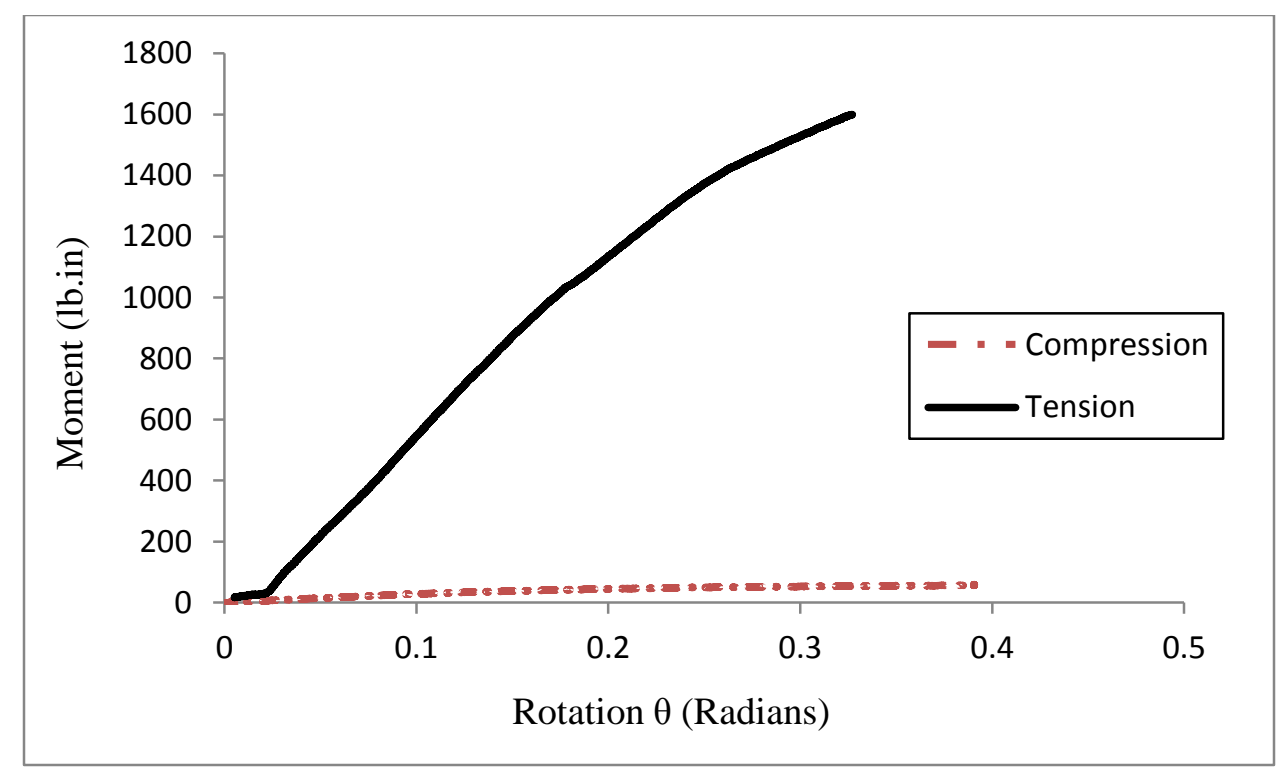

Figure 2-11- Moment-rotation diagrams of hurricane-clips test in compression side and tension side 
When hurricane clips was in tension side, connection resisted against applied torque with the help of the underneath SP member attached. Therefore, combined wood and hurricane clip resistance made the value of the rotational stiffness $K$, for tension side greater than compression side. On the contrary, when hurricane clip was in compression side, the only object that resists against torque was the hurricane clip itself without any resistance from SP wood member, and therefore buckling of ties was the result of this resistant. Extremely small values of rotational stiffness $K$, was the outcome of this phenomenon.

Failure modes of truss-wall connections (Hurricane clips) are shown in Figure 2-12 (a) and (b). When hurricane clip was in compression side or in the direction of the applied torque (Figure 2-12 (a)), all force came from rotation of the member carried by the hurricane ties and there was no resistance by the $2 \times 4$ SPF member. Therefore, support wood member $(2 \times 4 \mathrm{SPF})$ did not incorporate in resistance against applied torque, then low rotational stiffness values were obtained. Buckling of the hurricane clips was observed in the tests.

When hurricane clips were in the tension side or opposite direction of the applied load, majority of loads coming from torque of the SP member were carried by the support member or SPF, as shown in Figure 2-12 (b). Therefore, wood resistance was added to the resistance of hurricane clips against existed torque or rotation force, and the results were high rotational stiffness values obtained after the test. 


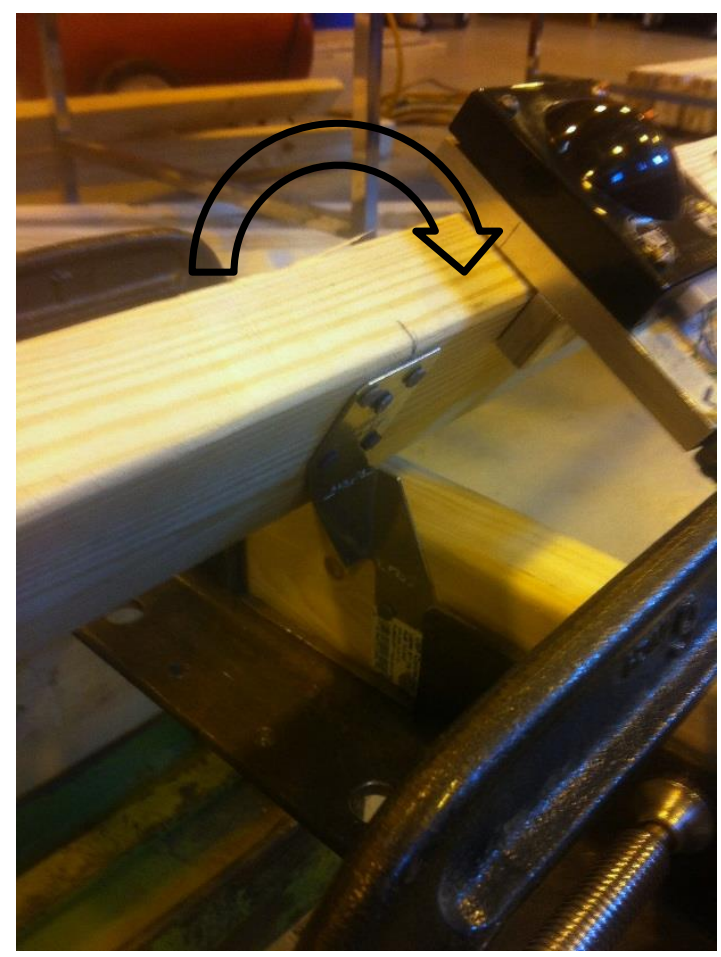

(a)

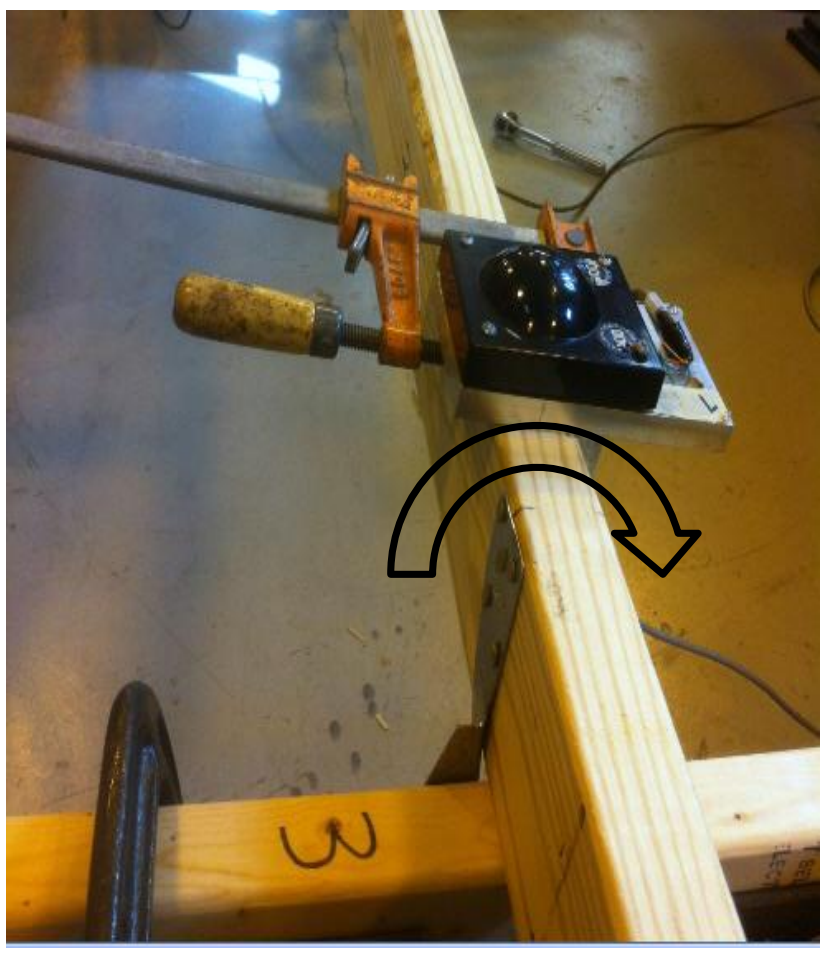

(b)

Figure 2-12- Failure modes of truss-wall connections in (a) compression and (b) tension side. Clockwise rotation of torsion actuator is shown in the picture

\subsection{Conclusion}

Rotational stiffness of two different methods of wood truss bracing as well as truss to wall connections were determined in this research. Lateral and diagonal bracing attached using two nails were two conventional bracing methods of metal plate connected wood trusses in building construction that was of interest in this research as well as hurricane clips as truss end supports. Appropriate database of rotational stiffness values are required for further modeling of truss assemblies structures and taking the semi-rigid effect of connections into account. The rotational stiffness of lateral bracing was 3 times greater than diagonal bracing since horizontal placement of the nails provided good resistance against the load. Pull out and bending of the nails were observed in the experiments. When hurricane clips attached to the direction of applied load the lowest rotational stiffness values among all bracing types tested were recorded and buckling of hurricane 
clips was observed. While hurricane ties were in tension, the greatest rotational stiffness values were achieved. Addition of the support resistance to resistance of the hurricane tie was the reason of the large rotational stiffness values. 


\subsection{Paper Two: Analysis of Metal Plate Connected Wood Trusses under Out of Plane Loads Caused by Personal Fall Arrest System}

\subsection{Literature Review}

\subsubsection{Structural Behavior of MPCWT Assemblies}

Trusses are defined as structures containing steel or wood structural members connected at joints referred to as nodes (Kassimali 2010). Forces in truss members are the result of external loads and reactions subjected to the truss which in classical truss theory, are assumed to act only at the nodes resulting in tensile or compressive forces. Due to the restrained condition of joints, truss members are not designed to carry out-of-plane loads (Kassimali 2010). However, in practice, truss members do carry some bending loads as a results of design or construction and service loads.

Metal plate connected wood trusses (MPCWT) are popular structures in residential construction as the main choice for roof assemblies. Analysis of these structures in an assembly system and under various loads such as in-plane and out-of-plane loads can help to comprehensively understand the behavior of MPCWT assemblies.

\subsubsection{In-Plane Loading Effects}

Gupta (2005) reviewed literature on the system behavior of wood truss assemblies. The behavior of individual trusses has been investigated in research papers in the past (Gupta et al. 1996) and system behavior of wood truss assemblies was not previously studied. To model the actual behavior of MPCWTs, a system design procedure (SDP) should be used which analyzes an assembly as a system and considers system behavior directly (Gupta 2005). The use of structural analysis software and three-dimensional (3D) analysis with actual geometry and construction conditions were recommended (Gupta 2005). The truss analog in the assembly and the geometry 
of roof system were influential parameters in the behavior of the real truss assembly; not exclusive or comparative of the variation in the individual member properties (Gupta 2005).

Wolfe and McCarthy (1989) tested two nine-truss assemblies with $28 \mathrm{ft}$. span in the design load range. Four loading units were used for each truss to simulate gravity load for stiffness outside the assembly. Stiffer trusses carry a greater amount of the load in the assembly. The load-deflection behavior in the assembly was approximately linear and within design loads, and the average truss deflection in the assembly was $50 \%$ lower than that of an individual truss alone. Moreover, the average failure loads increased $20 \%$ within the assembly, as compared with individual trusses under same gravity loads (Wolfe and McCarthy 1989).

Wolfe and LaBissoniere (1991) evaluated two nine-truss assemblies in two different tests and showed that interactions of truss members and braces within the truss assemblies controlled the deflections of members since repetitive member roof assemblies behaved similar to parallel systems. When the top chord of a truss was loaded to the design load, the loaded truss carried only $30-60 \%$ of the applied load and distributed $40-70 \%$ of the load to the adjacent unloaded trusses through the plywood sheathing (Wolfe and LaBissoniere 1991).

Underwood et al. (2001) studied the permanent bracing of MPC roof trusses. The required net lateral restraining force to brace multiple webs or chords was determined with one or more continuous lateral bracing (CLBs). Furthermore, a methodology for the permanent bracing design using a combination of lateral and diagonal braces was developed. Permanent and temporary bracing are crucial for safety purposes during erection and also for good performance of roof truss structures during service life (Underwood et al. 2001). The SAP 2000 was used as modeling software and in "structural analogs" pin or roller connections were used to represent the member 
end conditions. Results of modeling revealed that the behavior of MPC roof trusses should be studied in an assembly with proper bracing rather than as a single truss (Underwood et al. 2001).

To analyze the system effects of a MPCWT assembly, a system design procedure (SDP) was created by Gupta et al. (2004). The SDP is a program that has the ability for three-dimensional analysis of assemblies considering system effects directly. Gupta et al. (2004) compared combined stress indices (CSI) of individual trusses from the conventional design procedure (CDP), based on single truss design, with the resultant CSI from SDP analysis. Various system-related parameters such as bracing interaction of subassemblies and boundary conditions strongly influenced the behavior of the entire assembly-factors usually not considered in CDP (Gupta et al. 2004). The SAP 2000 structural analysis software was used to model assemblies and the results were in good agreement with experimental works of Wolf et al. (1986) and Wolf and McCarthy (1989) (Gupta et al. 2004)

Song (2009) conducted a study of the stability and reliability analysis of MPCWT assemblies. The assembly test used five trusses on a steel frame bolted to the concrete floor. The compression load was applied to the truss top chords using load actuator and wire- pulley system. Also, full scale experimental tests were conducted to provide input parameters and further verification for developed software results. Trusses were placed in a way that clearance of $471 \mathrm{~mm}$ under the trusses ensured enough space for bottom chord deflection. Four sets of actuator and wire pulley system were used as a loading system and load and deflection were recorded in several desired points (Song 2009). The SATA computer program based on the finite element method (FEM) was used in order to perform three-dimensional nonlinear structural analysis of the truss assembly. The out-of-plane rotational stiffness of the MPCWT connections had an increasing effect on the maximum load carrying capacity of the truss assembly (Song 2009). The critical 
buckling load could be doubled on the basis of an ideally pinned compression web, and the lateral bracing force was less than $1 \%$ of the bar forces from the test results and numerical analysis (Song and Lam 2012). The results of material property and truss plate connection testing were used as input variables for FE analysis software. Good agreement was found between truss assembly and FE model. An FE software can sufficiently be used to examine different material properties and different truss configuration in a more cost efficient manner (Song 2009).

\subsubsection{Out-of-Plane Loading Effects}

Previous research on MPCWTs has emphasized truss and joint analysis for in-plane loading (Wolfe and McCarthy 1989, Wolfe and LaBissoniere 1991, Underwood et al. 2001, Gupta et al. 2004, Gupta 2005, Song 2009, Song and Lam 2012). However, little research regarding outof-plane loading has been published. Wind forces during construction have been recognized as the reason of truss assembly failure, certainly when inadequate bracing is also incorporated (Hagan 1993).

Bohnhoff (2001) studied the lateral movement of MPCWT under wind load as a cause of out-of-plane movement. A sheathed end truss was subjected to a wind load modeled as a static

pressure. Simplified equations were presented to calculate bracing forces and required spacing of bracing elements to minimize deflection of the end truss (Bohnhoff 2001).

In MPCWT assemblies, bracing type and truss configuration performs an important role on the behavior of the assembly (Morris 2013), particularly when permanent bracing in early stage of construction is the focus of study (Underwood et al. 2001). Therefore, researchers conducted some studies on bracing and truss wall connections in various truss configuration and styles to understand the role of connections stiffness in wood truss assemblies. 
DeRenzis et al. (2012) tested nine full size roof systems with various combinations of outof-plane and uplift loads and various truss heel details. The goal was to evaluate lateral capacity of the roof-to-wall connections in the direction parallel to the ridge. All trusses were connected to the top plate of the supporting walls using H2.5T hurricane clips (DeRenzis et al. 2012).

High-heel trusses sheathed with oriented strand board (OSB) yield similar performance to that of the unblocked, low-heel trusses currently allowed by the IRC code (DeRenzis et al. 2012). High-heel truss assemblies braced with OSB sheathing and a reinforced ceiling diaphragm had the greatest ultimate load among other configurations as well as the greatest initial stiffness at roof peak. Trusses with OSB sheathing were superior to trusses with solid, intermittent blocking used in high-wind regions. Additionally, buckling and rotation of hurricane clips created rotation of the truss assembly during loading (DeRenzis et al. 2012).

\subsection{Out-of-Plane Loads Caused by Personal Fall Arrest System}

Out-of-plane loads on the MPCWT can be created by wind loading but can also be caused by a fall arrest anchor (Koch et al. 2014). Especially at early stages of construction when trusses are unsheathed, fall arrest anchor loads maybe critical. Fall arrest anchors are used to support personal fall arrest systems (PFAS). A PFAS is attached to a worker to provide protection in the event of a fall to lower level (Ellis 2011). Fall arrest anchors are usually attached to structural components such as trusses in roofs or studs. However, the strength of any fall arrest system anchor is related to the attached member location in the structure, and the load path to transfer the force through the structure (Hindman et al. 2013). The Occupational Safety and Health Administration (OSHA) specifies the minimum requirement and capacity of anchor attached to a structure that shall be capable of supporting at least $5000 \mathrm{lbs}(22.2 \mathrm{KN})$ per employee attached or designed, installed and used as part of a complete personal fall arrest system or under a supervision of a 
trained person (OSHA 2011b). Residential construction uses MPCWTs as well as PFAS for workers safety. Trusses that are used in residential construction job sites should be studied with more consideration as potential elements under out-of-plane loads (Koch et al. 2014).

Kaskutas et al. (2009) performed audits at 197 unionized, residential work sites to observe and tabulate hazards that could cause falls in residential construction. Truss installation methods existing in OSHA standards were rarely used in work sites due to difficulty of using guidelines or the time typically required (Kaskutas et al. 2009). Among a number of factors that may affect the strength of PFAS attached to a truss assembly system, appropriate bracing was a crucial factor that highly recommended for improvement (Morris 2013). Bracing must provide integrity to the assembly and the structure must be strong enough to resist loads induced by a PFAS anchor loading. The Structural Building Component Association (SBCA) have guidelines to properly and safely use of structural components. One guideline is dedicated to handling, installing, restraining and bracing of the MPCWT during construction (SBCA 2012).

Koch et al. (2014) tested the behavior of single monoslope queen wood trusses under horizontal out-of-plane loading. Failures of the trusses occurred at the truss-wall connection resulting in rotation of the truss about the horizontal axis, or brittle failure of the bottom chord. Rotational stiffness of the truss-wall connection was an influential factor that may be considered in future modeling of trusses under lateral loads (Koch et al. 2014).

Morris (2013) experimentally tested the behavior of a five roof truss assembly under fall arrest loads considering different anchor types and bracing configurations (Morris 2013). Trusses with slopes of 4:12 were used as testing materials with $2 \times 4$ southern pine members. Three types of chord bracing were compared, including wood bracing placed between the top chords, wood bracing placed continuously over the top chords of the trusses, and an engineered steel brace placed 
between the top chords. All bracing types were considered as temporary continuous lateral bracing (SBCA 2012). Also, a diagonal 2x4 extending from peak to eave on either side of the truss assembly was used for diagonal bracing. Figure 3-1 is a photograph of the test configuration (Morris 2013).

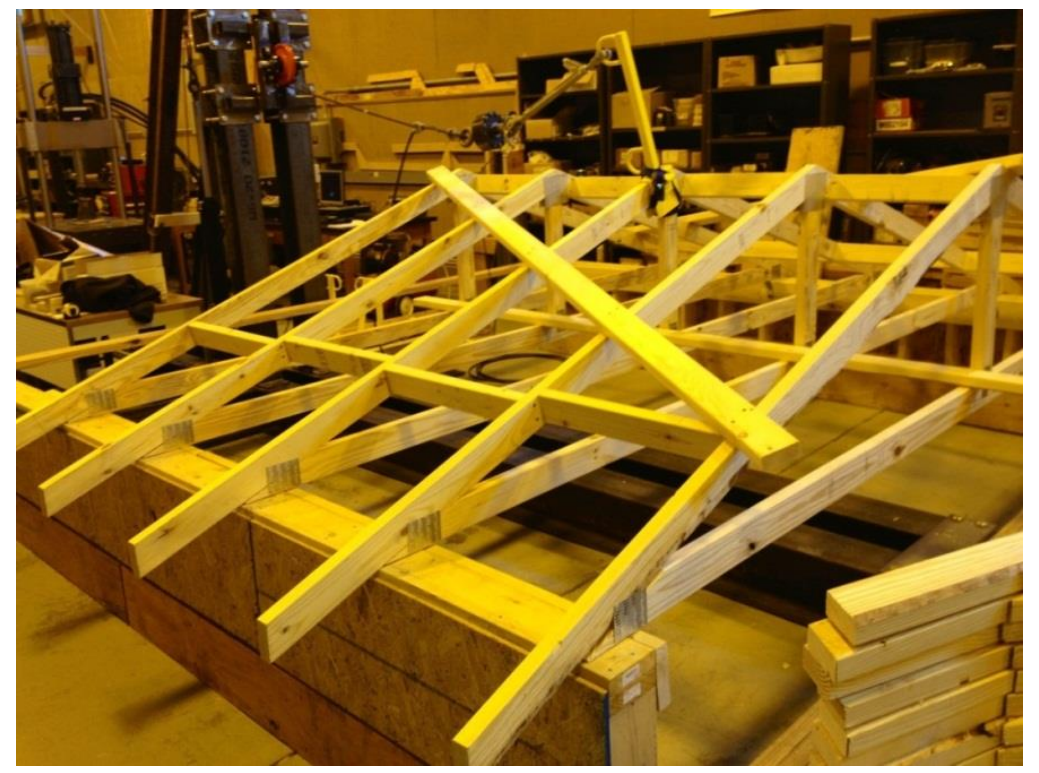

Figure 3-1- Five truss assembly showing wood bracing between top chords (Morris 2013)

Three different anchors were also compared - a non-commercial post frame construction anchor, a cross-arm strap and a three-truss spreader bar. The cross-arm and spreader bar anchors are both available from safety equipment suppliers. An out-of-plane horizontal load was applied to the truss assembly (Figure 3-1).

Full scale truss assembly testing results of Morris (2013) are summarized in Table 3-1. The post frame anchor had the lowest maximum load due to the attachment to a single truss. Furthermore, the post frame anchor was the only anchor which failed. Compared to the other anchors, the cross-arm strap with in-between wood bracing had the greatest ultimate load, and the cross-arm strap was the only anchor which did not fail during testing. The spreader bar had the 
greatest average load among three different anchors, but yielding of the spreader bar occurred in every single test, requiring replacement of the damaged anchor (Morris 2013).

Table 3-1. Summary of maximum loads and deflection from Morris (2013)

\begin{tabular}{|c|c|c|c|}
\hline Bracing Type & Ultimate Load (lbs.) & $\begin{array}{c}\text { First Truss Top } \\
\text { Chord Deflection (in) }\end{array}$ & Failure Mode \\
\hline \multicolumn{4}{|c|}{ Post Frame Anchor } \\
\hline Wood in-between & 726 & 1.847 & Post frame anchor \\
\hline Wood on-top & 752 & 2.577 & On-top bracing \\
\hline Engineered Steel & 571 & 3.933 & Engineered steel bracing \\
\hline \multicolumn{4}{|c|}{ Cross-Arm Strap } \\
\hline Wood in-between & 1,412 & 5.066 & Truss plate at anchor point \\
\hline Wood on-top & 875 & 3.766 & On-top bracing \\
\hline Engineered Steel & 1,084 & 4.975 & Engineered steel bracing \\
\hline \multicolumn{4}{|c|}{ Spreader Bar Anchor } \\
\hline Wood in-between & 1,245 & 4.206 & Truss plate at anchor point \\
\hline Wood on-top & 1,320 & 4.645 & On-top bracing \\
\hline Engineered Steel & 919 & 13.660 & Engineered steel bracing \\
\hline \multicolumn{4}{|c|}{ Additional Testing (Cross-Arm Strap) } \\
\hline Wood in-between & 1,812 & 7.878 & Defect in outside truss \\
\hline Wood in-between & 2,436 & 8.564 & $\begin{array}{c}\text { Bottom chord of outside } \\
\text { truss }\end{array}$ \\
\hline
\end{tabular}

The in-between wood bracing was the most reliable form of bracing and had the greatest ultimate loads. The wood in-between bracing did not catastrophically fail in any of the tests. The on-top bracing did not perform well as the in-between bracing due to withdrawal from the top of the truss which caused a loss of support for the structure. The commercial engineered steel braces were easy to install, but the maximum load was less than other bracing types and bracing failure occurred during the tests. 
Based on the previous results, two additional tests were performed with in-between bracing and cross-arm strap anchor with the addition of sway bracing along truss the webs. Lateral bracing was placed at the location of the anchor to reinforce the location of the applied load. Results of these tests are also presented in Table 3-1. The highest ultimate load among all testing were recorded in the two additional tests. Therefore, truss assembly test with wood in-between bracing and the additional test truss assembly with sway bracing were taken as the major truss configurations for the validation study and modeling.

Performance of MPCWT assemblies in the range of design loads have been investigated previously. Considering out-of-plane lateral loads such as wind or impact loads, as well as paying special attention to truss bracing and truss-wall connections, there is a need to study these structures particularly during early construction phases (Koch et al. 2014, Morris 2013). The goal of this paper was to model and validate the MPCWT truss assembly with test results from Morris (2013) using structural analysis software and joint stiffness values obtained in Paper 1. The experimental results of Morris (2013) were the main source for modeling and validation study in this research. A parametric study was conducted after model validation considering truss length, load location and bracing stiffness considering the effects upon a MPCWT assembly subjected to out-of-plane lateral loads.

\subsection{Materials and Methods}

\subsubsection{Modulus of Elasticity Measurement}

Modulus of elasticity of the $2 \times 4$ SPF and SP members was determined using conventional three-point bending tests. Fifteen specimens of each species were loaded $(P)$ by a $50 \mathrm{lb}$ weight and deflection at the midspan was measured using a BAKER Gauge JB50 dial gauge with 1 inch maximum sensitivity of \pm 0.001 . Then, using the following equation, MOE was calculated: 


$$
E=\frac{P L^{3}}{48 I \delta}
$$

where $L$ is span length (45 in), $I$ moment of inertia and $\delta$ is deflection at midspan. Then, using the equation in ASTM D5457, modulus of elasticity for stability $\left(E_{\text {min }}\right)$ for sawn lumber was calculated using the MOE and COV values.

$$
E_{\min }=\frac{1.03 E\left(1-1.645\left(C O V_{E}\right)\right.}{1.66}
$$

where $E$ is modulus of elasticity and $C O V_{E}$ is the coefficient of variation. The calculated modulus of elasticity and modulus of elasticity for stability $\left(E_{\min }\right)$ were used in the member properties for comparison to the models with default National Design Specification for Wood Construction (NDS) material properties (AWC 2012). Calculated MOE and $E_{m i n}$, are shown in Table 3-2. There is $18 \%$ difference between experimentally determined MOE values and the values reported in the NDS. Sample size and the environmental condition that the MOE tests were conducted, may are the reasons of the obtained percent of difference.

Table 3-2. MOE and material properties of SP and SPF

\begin{tabular}{ccccc}
\hline & $E(\mathrm{Psi})$ & $C O V_{E}$ & $E_{\min }(\mathrm{Psi})$ & $E_{N D S}(\mathrm{Psi})$ \\
\hline SP & $1.19 \mathrm{E} 006$ & $20 \%$ & $4.92 \mathrm{E} 005$ & $1.4 \mathrm{E} 006$ \\
\hline SPF & $1.18 \mathrm{E} 006$ & $25 \%$ & $4.31 \mathrm{E} 005$ & $1.4 \mathrm{E} 006$ \\
\hline
\end{tabular}

\subsubsection{Structural Analysis Software}

The objective of this research was to validate a model using commercial structural analysis software to approximate the behavior of unsheathed truss assemblies loaded out-of-plane. Validation compared modeling of load-deformation behavior to experimental results in the linear elastic range. Visual Analysis (VA) software was used for modeling purposes. Visual Analysis is a structural analysis software package produced by IES, used to analyze structural engineering 
problems using matrix methods. The program contains a material library including a wide array of materials such as wood, steel, concrete, aluminum, cold-formed steel and masonry (IES, Inc. 2013).

Visual Analysis also has the ability to perform different analyses including: static, direct analysis (notional loads, stiffness reduction), dynamic analysis, superposition results and envelope, and plate forces. In addition, the software includes building codes related to each materials such as; American Institute of Steel Construction (AISC) and Canadian Institute of Steel Construction (CISC) for design of steel frames and trusses, National Design Specification for Wood Construction (NDS), Aluminum Design Manual (ADM), North American Specification for coldformed structures (NAS) and American Concrete Institute (ACI) for concrete beams, columns and slabs (IES, Inc. 2013).

\subsubsection{Analog Description}

To validate the modeling with experimental results, two different structural analogs were created. Both models are similar to the tests conducted by Morris (2013). In the first model, lateral bracing and diagonal bracing with a strap anchor which is considered as standard test without improvement was constructed representing the cross-arm strap with in-between bracing. The second model was the model with lateral bracing at the location of the strap and additional sway bracing at the location of the truss webs representing the improved test with cross-arm strap and in-between bracing (Figure 3-2). In this model a set of sway bracing was created using $2 \times 4 \mathrm{SPF}$ lumbers that are attached to all truss webs and again was similar to the experimental test.

The analog accounted for truss members, bracing members, and all connections within the trusses, bracing between trusses, and support connection to the walls below. This section describes the structural analysis software package used, the analog structures, member properties and joint 
characteristics used. The roof truss used in the model validation was the same as the truss used by Morris (2013) (Figure 3-2).

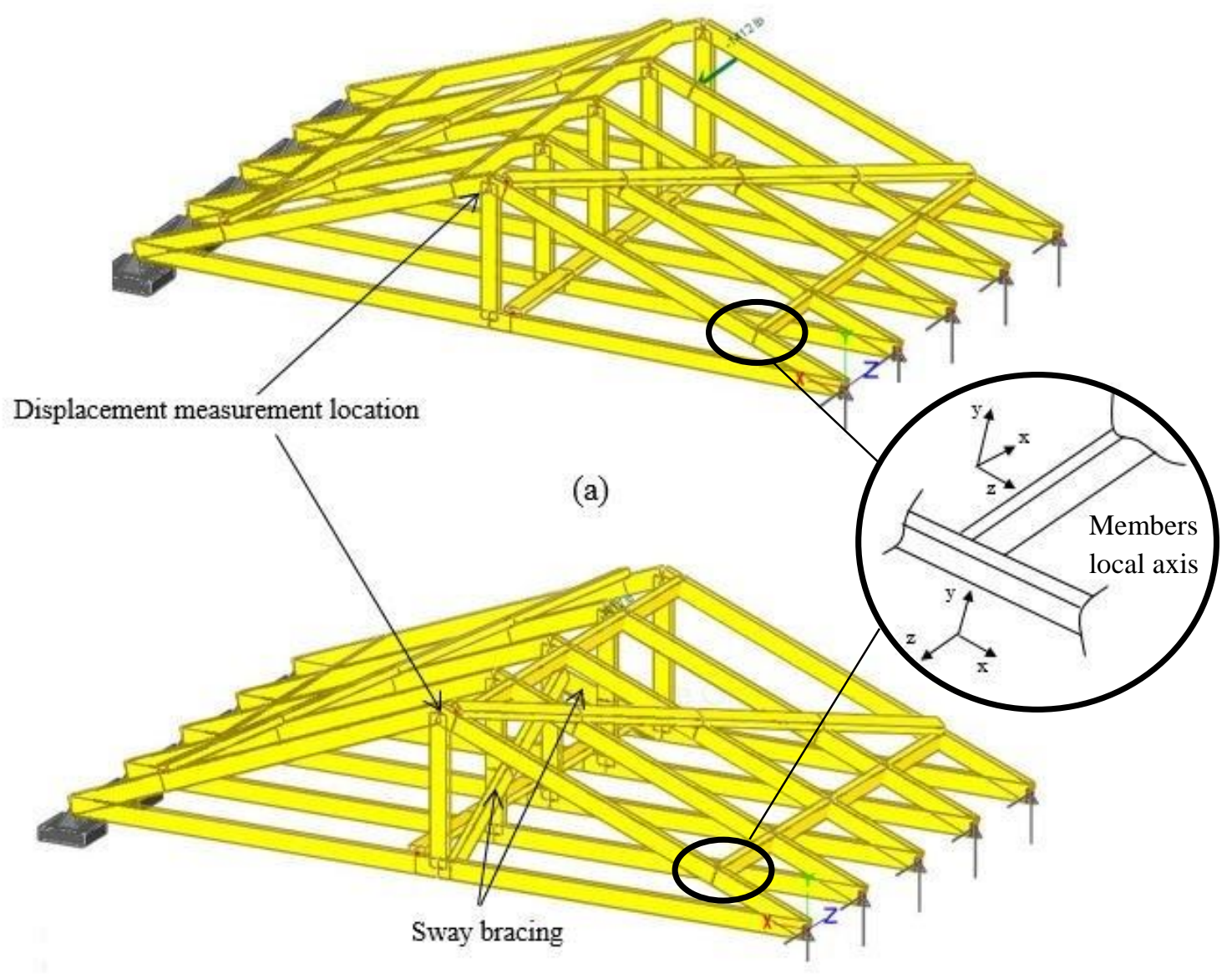

(b) 


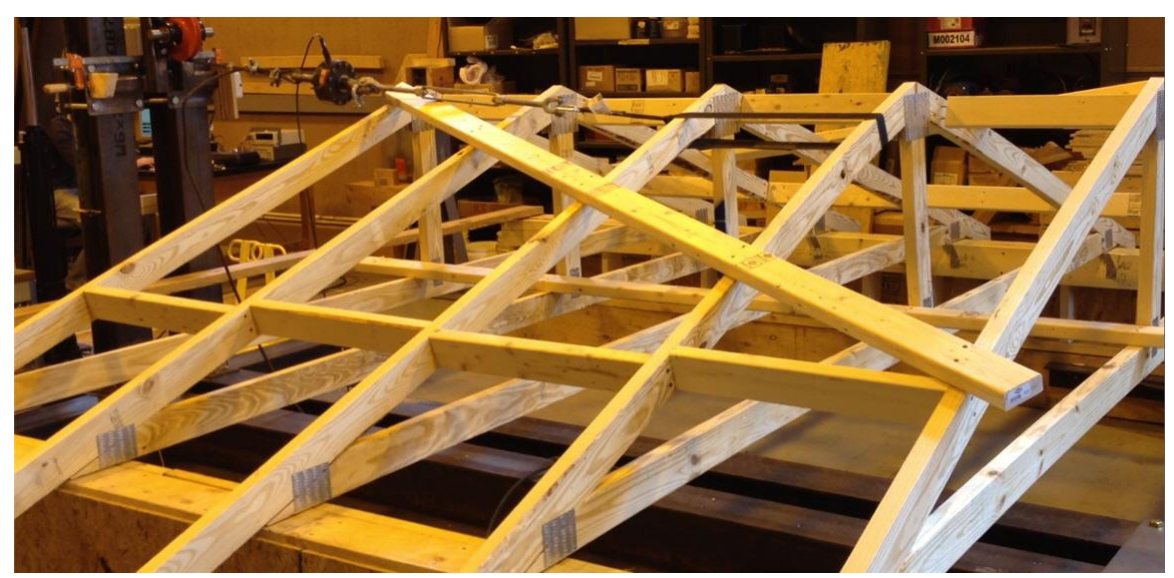

(c)

Figure 3-2. Structural analog of five truss assembly constructed in VA and experimental set up as conducted by Morris (2013); (a) Morris "standard" model, (b) Morris "improved" model, and (c) Experimental set up of standard model

The truss was a $13 \mathrm{ft}$. span king post with a 4:12 pitch. Structural analogs of the five truss assembly described in Morris (2013) shown in Figure 3-2 from the VA software. By default, the software has material properties for wood products based on the NDS (AWC 2012). Nominal Southern Pine (SP) No.2 2x4 dimension lumber (full sawn) was used for truss members and No. 2 Spruce Pine Fir (SPF) 2x4 lumber for the braces. Two model assumptions with different modulus of elasticity ( $E_{N D S}$ and $E_{M E A S}$ ) values were evaluated, as presented in Table 3-2. In the first model, NDS material property $\left(E_{N D S}\right)$ was assigned to the model. In the second model, the material property was modified and measured modulus of elasticity $E_{M E A S}$, and modulus of elasticity for stability $E_{\min }$, replaced with default values based on the NDS.

Trusses were spaced 24 inches on center, with continuous lateral and diagonal bracing. The lateral bracing was located between each truss at $1.62 \mathrm{ft}$. at both side of the assembly near the support and at $0.5 \mathrm{ft}$. at left top of the trusses. A single diagonal bracing element was placed on each top face located on the top chord of the trusses. A sensitivity study before the actual validation study showed that nails in diagonal bracing are important to be modeled since the out-of-plane 
load caused shear forces in the connections. Therefore, in order to account for shear forces in the joint location of diagonal bracing, the nailed connections were also modeled. Two $16 \mathrm{~d}$ sinker nails with 0.16 in diameter and 3.5 in long were used for attaching the diagonal bracing. The model considered a single nail with material properties equivalent to two nails, approximated as steel rods with grade of ASTM A36.

In order to stabilize the model, one end of the trusses was assumed pinned, transitionally fixed in $X, Y$ and $Z$ direction regarding to the global axis in Figure 3-2, and the other end assumed as a roller support, which is transitionally fixed in $Y$ and $Z$ directions again based on the model global axis. One consistent assumption of both the modeling and the experimental work is that the deformation of the stem wall was considered negligible.

The location of simple and rigid connections are shown in Figure 3-3 and also connection stiffness assumptions for each member in the truss assembly are represented in Table 3-3. Simple connection known as hinged, are connections fixed in 3 translational directions regarding to the member local axis, but the rotation was free about members $y$ and $z$ directions (Figure 3-2). Rigid connection assumptions did not allow any translation or rotation to the member, again considering member local axis (Figure 3-2). Connections assumption in the truss assembly was discussed in next paragraph.

In the analog, truss webs were assumed as simple connections. Truss lateral braces were assumed as simple connections with rotational stiffness value of lateral bracing determined in the Paper 1. Diagonal braces were assumed as rigid connections, again with experimentally determined rotational stiffness values from Paper 1. Truss chords has different assumptions regarding to their connection position. For example, truss chords near the end supports (with rotational stiffness values from Paper 1) and at the peak of the truss, were assumed as simple 
connections to simulate the effect of metal plates in those locations, but truss chords at connection location with bracings (lateral and diagonal) were assumed as rigid. However, since metal plate in the bottom of the web was very narrow, only truss web assumed as simple and truss bottom chord at that location was assumed as rigid connection. Keeping some connections in the assembly as rigid (Figure 3-3) is crucial, otherwise the stability of the model could not meet and convergence error could occur. The obtained values of rotational stiffness from Paper 1 in $z$ and $y$ directions (Regarding members local axis) are 89.51 and $21.44 \mathrm{lb}$.in/degree for lateral and diagonal bracing respectively, and 100.54 and $3.06 \mathrm{lb} . \mathrm{in} /$ degree for truss-wall connection in $y$ direction in tension and compression side, respectively.

Consultation with a professional engineer who uses Visual Analysis for wood truss modeling purposes confirmed that simple and rigid connection assumptions are conventional in engineering practices for truss modeling (Leatherman 2014). As explained earlier, to accurately simulate metal plate connections, the location of metal plates was assumed to be a simple connection except the connection location of the truss web and bottom chord (Figure 3-3). Simple connection assumption allows rotation of the member in both the strong and weak directions $(y$ and $z$ local axis directions according to Figure 3-2).

Table 3-3- Analog members with connection assumption types

\begin{tabular}{ccc}
\hline Member & Species & Connection Type $^{1}$ \\
\hline Truss webs & Southern pine & Simple \\
\hline Truss chords & Southern pine & $\begin{array}{c}\text { Simple and rigid with rotational } \\
\text { stiffness values for bottom chord }\end{array}$ \\
\hline Lateral bracing & Spruce pine fir & $\begin{array}{c}\text { Simple with lateral rotational stiffness } \\
\text { values }\end{array}$ \\
\hline Diagonal bracing & Spruce pine fir & $\begin{array}{c}\text { Rigid with diagonal rotational stiffness } \\
\text { values }\end{array}$ \\
\hline${ }^{1}$ Rotational stiffness values were determined in the experimental tests in the Paper 1.
\end{tabular}




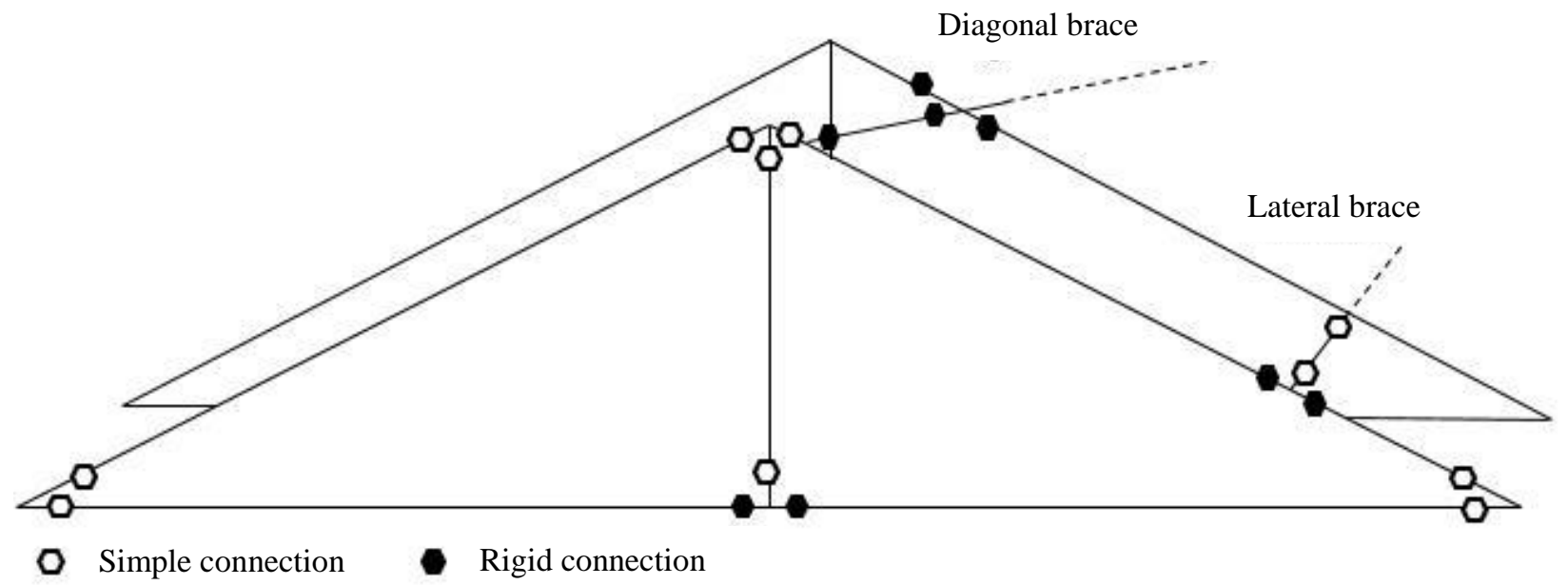

Figure 3-3- Location of simple and rigid connections in the truss assembly

\subsubsection{Joint Stiffness}

To accurately simulate a structural analog containing various connection type, semi-rigid assumption with actual stiffness of the members should be considered. For this purpose, rotational stiffness of truss assembly connections, including lateral and diagonal bracing as well as truss-wall connections were determined using experimental tests discussed in Paper 1. After construction of the model, results of the rotational stiffness testing (Paper 1) were incorporated into the models using the 'Joint Modify' Tab in VA. Actual behavior of joints was considered with taking joint behavior as semi-rigid, with constant stiffness values as measured in the experiment. As explained earlier, end supports were restrained in vertical and horizontal directions in order to simulate roller and pinned connections and also the experimentally determined stiffness values were considered in end supports as well.

\subsubsection{Model Load and Response}

The cross-arm strap anchor was simulated on the fourth truss from the loading direction using a point load applied out-of-plane to the truss in the same direction as the experimental load 
(Figure 3-2). The load was static and no dynamic behavior was considered. This condition was similar to the load applied by Morris (2013). A single point load at the location of cross-arm strap anchor was applied to the truss assembly to simulate the out-of-plane loading on trusses. Deflections at the top chord of the first truss and axial load in the members $F_{x}$, were of interest to be measured in truss assembly as a response of the analysis.

\subsubsection{Validation of the Model and Experiment}

Validation allows researchers to trust simulation results and conduct further modeling without requiring extensive experimental work (Gupta et al. 2004). Morris (2013) measured the displacement of the truss assembly at the truss peak and the rotation of the bottom chord near the hurricane clips. Appropriate validation of the two structural analogs and three joint stiffness combinations is discussed in the next paragraphs.

To validate the results of the modeling and experimental works, the maximum load measured by Morris (2013) was applied to each model. The deflection was measured at the peak of the first truss closest to the load cell (Figure 3-2).

The reasons that the stiffness and strength criterion were combined in this study are; (1) in the standard model, load deflection diagram was linear up to the failure load, so yield load was as same as failure load, and (2) there was no actual yield load in the experiment, since as observed the assembly tolerated load to a certain point, and after which failure eventually occurs, but in the numerical model, ultimate load obtained in the experiment was applied and therefore does not resemble the actual loading behavior of the experimental test. Usually, in research papers, differences below 5-6\% between results of experimental and modeling outcomes were considered as appropriate validation results (Gupta 2005). Therefore, in this paper to consider the results of the validation as appropriate, $\pm 5 \%$ tolerance for the deflection was considered a good result. 


\subsubsection{Parametric Study}

A parametric study considering some important parameters that may influence the behavior of MPCWT assemblies under out-of-plane loads was conducted after the models were validated with the experimental outcomes. Parameters of interest in the study were joint stiffness, fall arrest anchor location and dimensions of the trusses. These three independent studies were conducted for the "standard" and "improved" models.

\subsubsection{Joint Stiffness}

To examine the effect of joint stiffness on the behavior of the truss assembly, three different joint assumptions were assigned to the connections of the standard and improved models. The first assumption for the connection was exactly the same as validated models with measured rotational stiffness experimental test values for the joints. Then, the connections were changed to the simple (Hinged) and rigid assumptions (both assumptions discussed in section 3.2.2.1), respectively.

\subsubsection{Load Location}

The second parameter of interest in the parametric study was the location of load application in each truss assembly. The load was applied to the all trusses, at the top chord close to the truss peak, in the five truss assembly respectively, except the first truss (The first in the direction of load). The same loading conditions for the standard and improved model used in the validation study were applied.

\subsubsection{Truss length}

The third parameter that was studied in parametric study was the effect of increasing the truss span length and changing the web configuration on the behavior of the assembly. Tested MPCWT models in VA and the loading point in the structure are illustrated in Figure 3-4. The 
same loads were applied to the truss assemblies. Truss dimension was examined by changing the span of the trusses. Other factors such as load location, number and spacing between trusses remained the same as the validated models. Three different span lengths were studied, namely; 20, 25 and 30 foot spans. In all trusses the pitch of the trusses remained the same at 4:12 and all unbraced truss chord and web lengths were limited to 7 feet to prevent buckling of chords. Lateral and diagonal bracings of interest to be studied were numbered as A1 (top left diagonal brace) and B1 through B4 (right lateral braces) in all trusses with different span lengths.

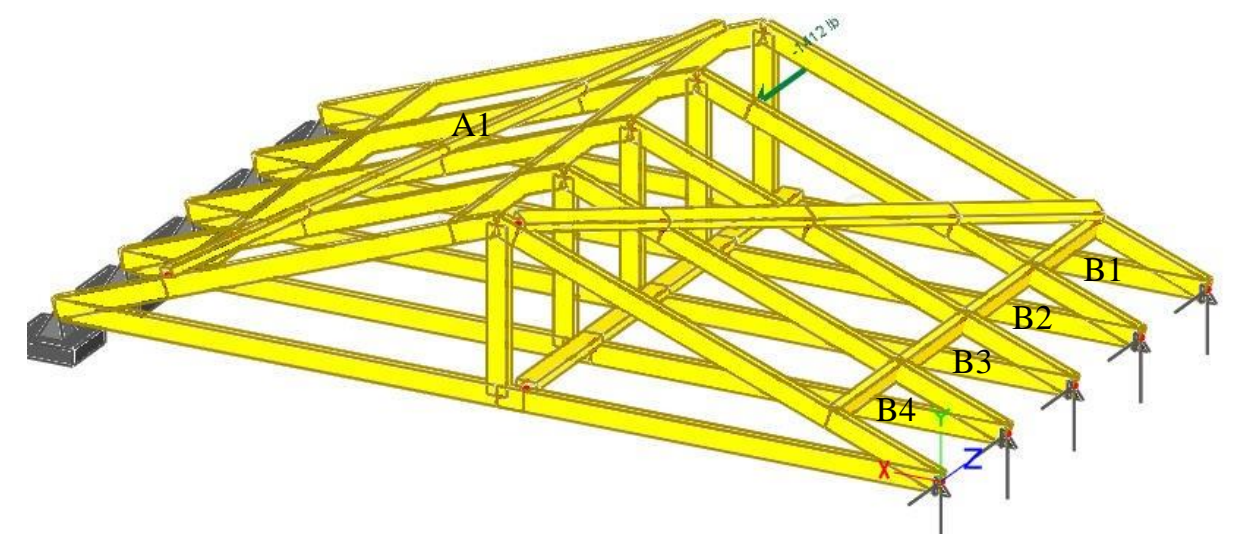

(a) 13 feet long

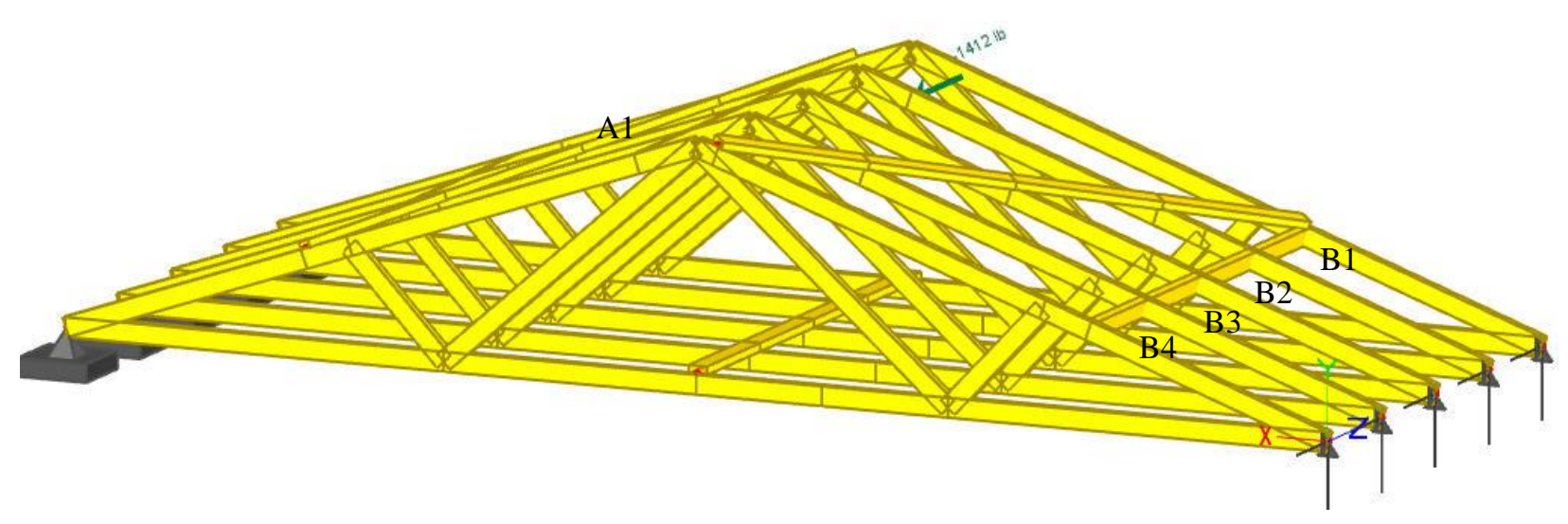

(b) 20 feet long 


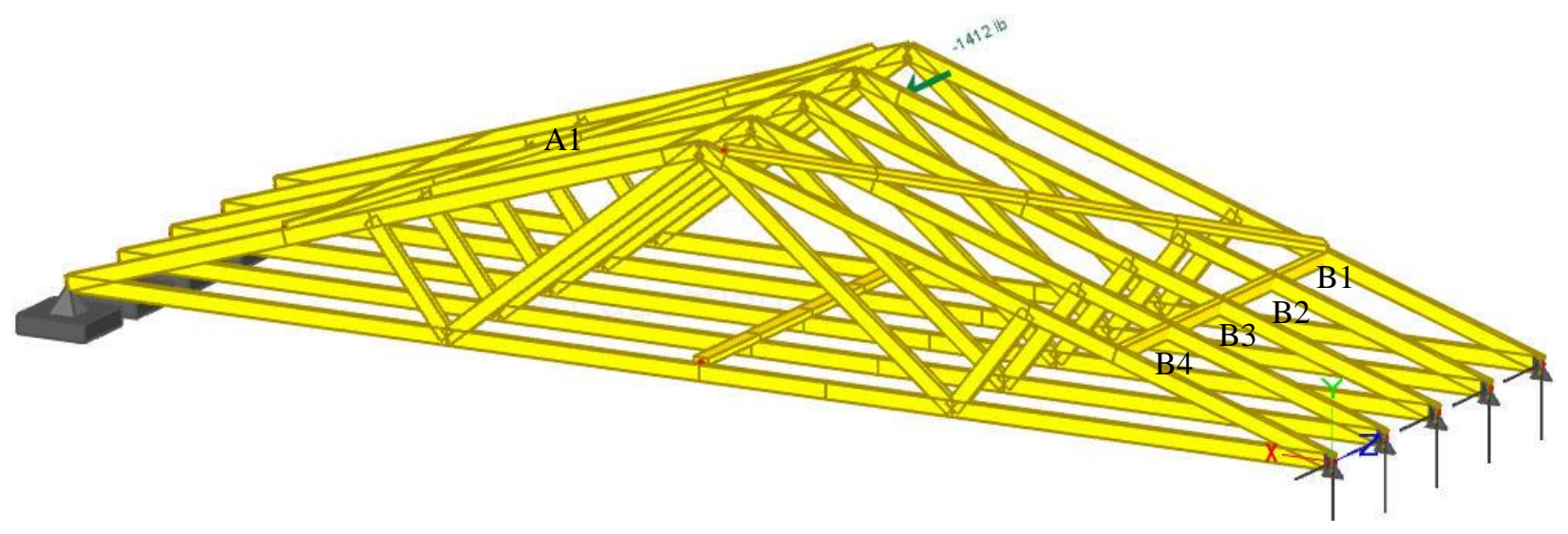

(c) 25 feet long

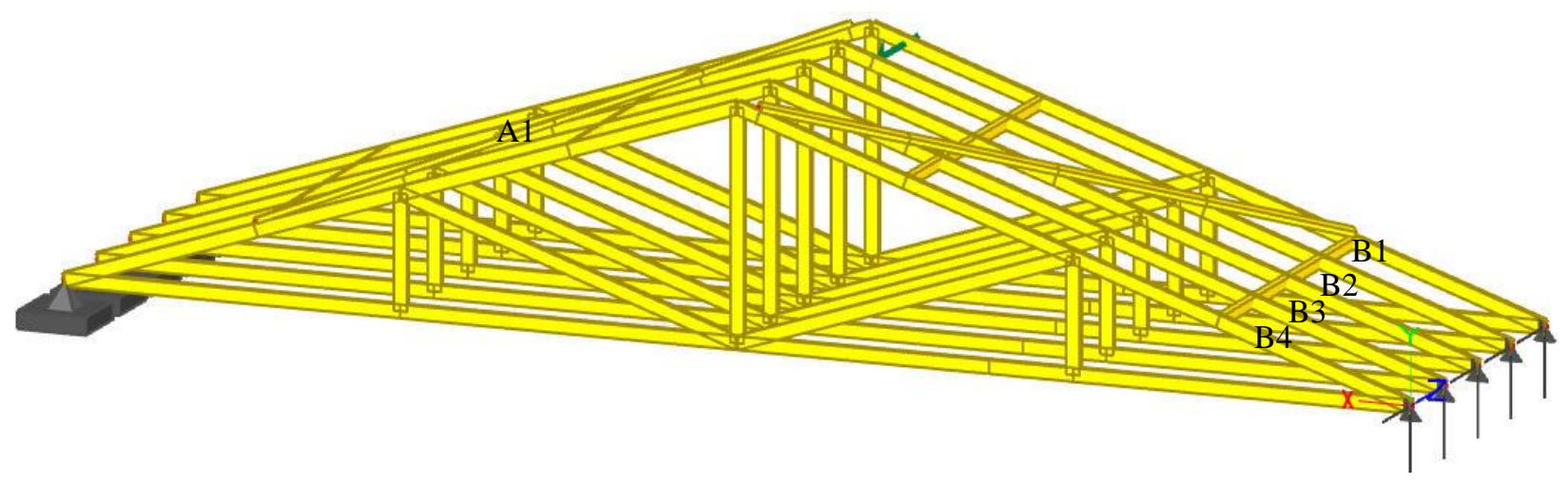

(d) 30 feet long

Figure 3-4. Four different truss lengths to be studied. 


\subsection{Results and Discussion}

\subsubsection{Validation Study}

The results of the validation study are shown in Table 3-4. The magnitude of load was kept the same in both the experiment (Table 3-1) and the models. For the "standard" model with $E_{N D S}$, a 3.25\% difference was observed in the measured displacement. The model with determined $E_{M E A S}$ values has a difference of $8.35 \%$ with experimental results. In the improved model, a $3.07 \%$ difference was recorded for the model with $E_{N D S}$ values and a $10.15 \%$ difference was obtained for the model with determined $E$ values. Therefore, all standard and improved models with $E_{N D S}$ values, are validated with the experimental outcomes with less than $4 \%$ difference. These percent differences are lower than the specified 5\% difference allowed to be considered as a good validation for this paper. Since $\mathrm{E}_{\mathrm{MEAS}}$ values were $18 \%$ less than $\mathrm{E}_{\mathrm{NDS}}$, thus stiffness of the materials was lower and higher difference was found in comparison with the experiment. All parametric studies were conducted on models with $E_{N D S}$ values. The model prediction in both cases is greater than the obtained experimental deflections which reveals that the model results are conservative.

Table 3-4. Validation study results; comparison of experimental and modeling displacement values at the peak of the first truss

\begin{tabular}{|c|c|c|c|c|c|c|}
\hline & \multicolumn{3}{|c|}{ Standard model } & \multicolumn{3}{|c|}{ Improved model } \\
\hline & Experiment & $\begin{array}{c}\text { Model with } \\
\mathrm{E}_{\mathrm{NDS}}\end{array}$ & Model & Experiment & $\begin{array}{c}\text { Model with } \\
\mathrm{E}_{\mathrm{NDS}}\end{array}$ & Model \\
\hline Ultimate load (lbs.) $)^{1}$ & 1412 & 1412 & 1412 & 2436 & 2436 & 2436 \\
\hline Displacement (in) & 5.066 & 5.231 & 5.489 & 8.564 & 8.836 & 9.433 \\
\hline $\begin{array}{c}\text { Percent of difference } \\
\text { with experiment }\end{array}$ & & $3.25 \%$ & $8.35 \%$ & & $3.07 \%$ & $10.15 \%$ \\
\hline
\end{tabular}

The model axial forces in the longitudinal direction $(F x)$ with respect to each member's local axis (Figure 3-2) are shown in Figures 3-5 for standard model and Figure 3-6 for improved 
model. Two diagonal braces as well as lateral bracing in the middle of the truss carried the maximum axial force in the longitudinal direction of each member. These results have good agreement to the experimental failure modes that were reported by Morris (2013), since nails pull out in the diagonal and lateral bracing were observed.

Axial forces on the right side lateral brace for both the standard and improved model were presented and compared in Table 3-5. In the standard model, the load in brace B2 was the highest among other braces and brace B4 has the lowest load. In the improved model, axial force in brace B1 was the greatest. A descending trend was observed in brace forces B1 through B4, with B4 having the lowest load. Since lateral braces near the loading location (B1 and B2) had more contribution in resistance against out-of-plane load, greater loads than the other braces were recorded. The same descending trend in brace's axial force was observed in improved model as well. However, because of the greater applied load to the improved model, the braces axial forces are greater than standard model (Table 3-5). Thus, axial loads in the lateral braces have direct relation with the amount of applied load to the structure.

Table 3-5. Axial forces in the right side lateral brace (lbs.)

\begin{tabular}{c|cccc}
\hline & B1 & B2 & B3 & B4 \\
\hline Standard model & 946 & 928 & 649 & 289 \\
\hline Improved model & 1459 & 1448 & 950 & 332 \\
\hline
\end{tabular}

The axial forces in the longitudinal direction in the right diagonal brace member of the standard model (1382 lbs.) was less than the improved model (2393 lbs.), since the applied load was higher in that model. The ratio of the greatest axial force to the applied load (1412 lbs.) in the standard model is 0.978 and this ratio in the improved model with applied load of 2436 lbs., is 0.982. Therefore, almost the same ratios were found in both models and thus can conclude that maximum brace forces are equal to the lateral applied load to the models. 


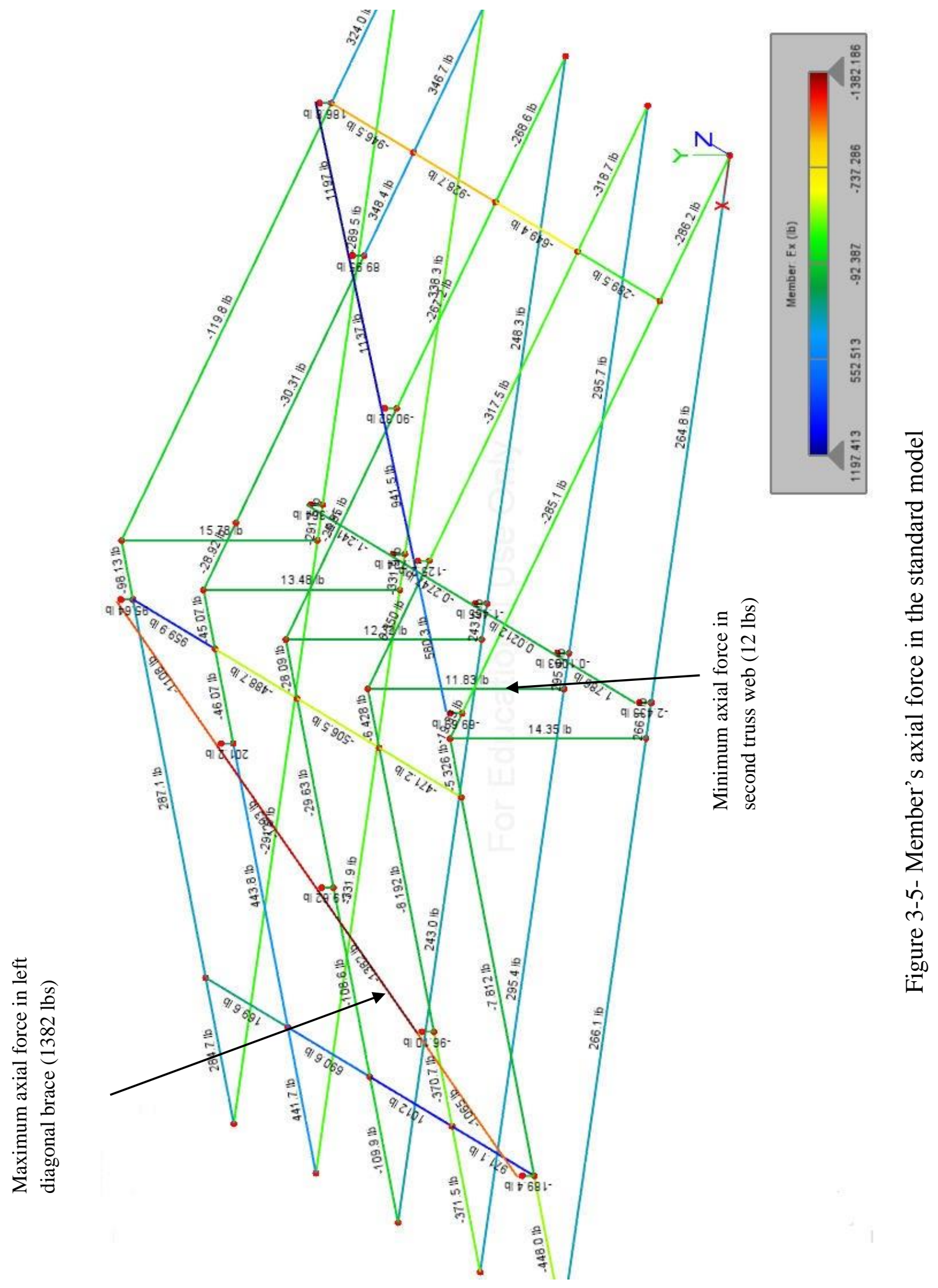




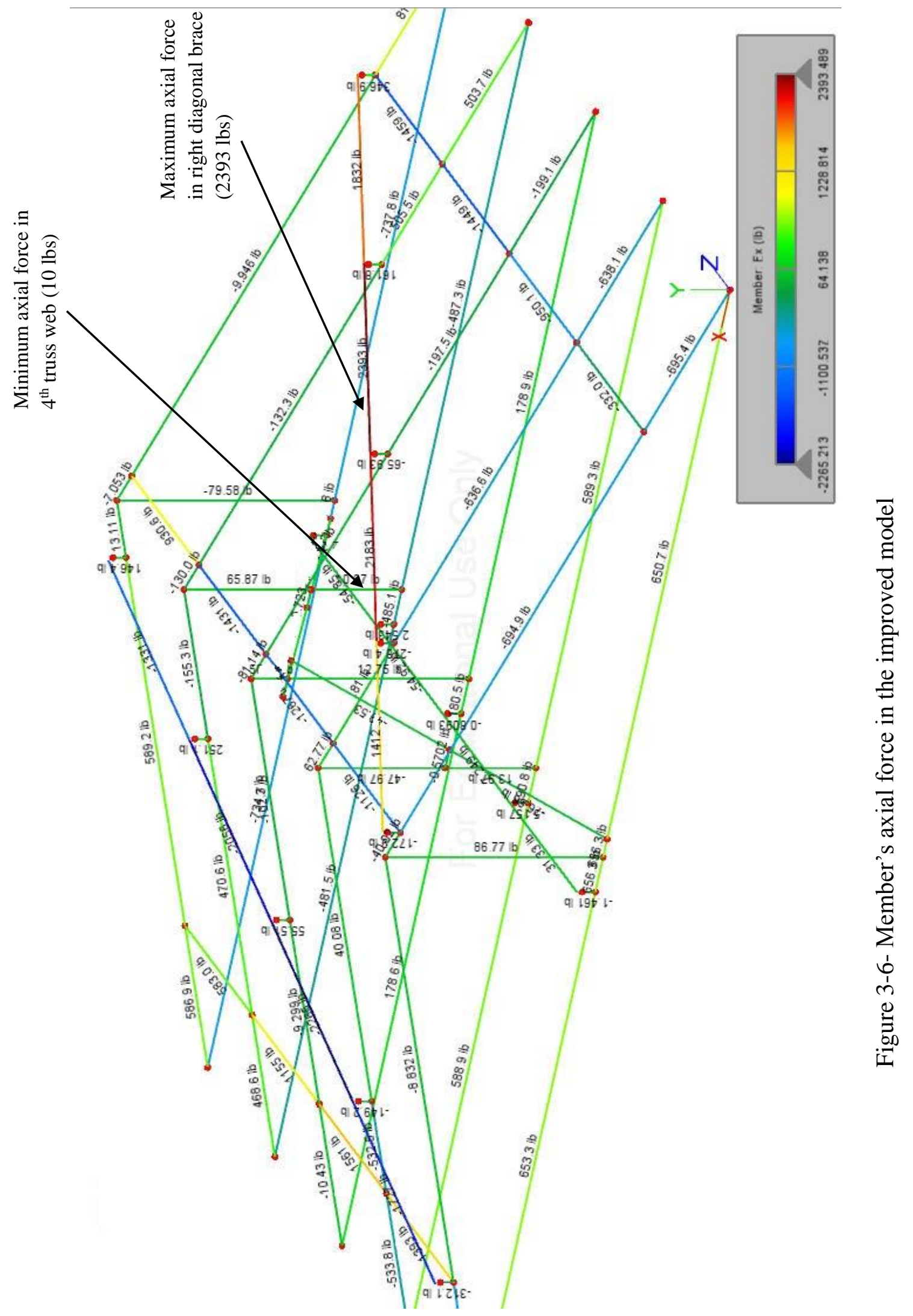


In both models load applied to the right side of the truss assembly (as represented in Figure 3-2), but as shown in Figure 3-5, in the standard model the maximum load occurred in the left diagonal brace (1382 lbs.), however, in the improved model maximum load was recorded in the right diagonal brace (2393 lbs.). Since the location of lateral bracing at the top of the trusses in the improved model was changed from left side of the assembly to the right side, and also two sway braces were added along the truss webs, therefore maximum axial force location was changed from the right diagonal brace in the standard model to the left diagonal brace in the improved model. Changing the load path by sway bracing and reinforcement of loading location by lateral bracing, are the reasons for observed changes in the improved model.

The $2^{\text {nd }}$ truss web in the standard model experienced the lowest axial force than other members $\left(12 \mathrm{lbs}\right.$.) and the minimum load in the improved model was in the web of the $4^{\text {th }}$ truss (10lbs.). Because of bracing configurations to resist and transfer loads and loading point location that was at the top of the fourth truss, it was acceptable for the truss webs of the $2^{\text {nd }}$ and $4^{\text {th }}$ trusses in the standard and improved model to experience the lowest loads.

\subsubsection{Parametric Study Results}

\subsubsection{Joint Stiffness}

Joints stiffness parametric study results were shown in Table 3-6. The ultimate loads were the same loads that were used in the model validation. In the standard model, when all connections were assumed as rigid, the displacement at the peak of the first truss was only $0.738 \mathrm{in}$. With hinges (Simple) joints at the location of the braces, the displacement at the peak of the first truss was 8.972 in. There was an 11 times the deflection difference between two different assumptions in standard model, when connections assumed as simple or rigid. This high percent of difference reveals the critical role of joint assumption in the analysis of truss assemblies. The rigid and simple 
joint assumptions in standard model have $586 \%$ and $77 \%$ difference with experimental results, respectively. Moreover, comparison of rigid and simple joint assumptions with validation study model displacement, showed $609 \%$ and $71 \%$ differences, respectively.

Table 3-6- Joint stiffness parametric study results

\begin{tabular}{|c|c|c|c|c|c|c|c|c|}
\hline & \multicolumn{4}{|c|}{ Standard model } & \multicolumn{4}{|c|}{ Improved model } \\
\hline Joint Stiffness & Experiment & Simple & $\begin{array}{c}\text { Validated } \\
\text { model }\end{array}$ & Rigid & Experiment & Simple & $\begin{array}{c}\text { Validated } \\
\text { model }\end{array}$ & Rigid \\
\hline $\begin{array}{l}\text { Ultimate load } \\
\text { (lbs.) }\end{array}$ & 1412 & 1412 & 1412 & 1412 & 2436 & 2436 & 2436 & 2436 \\
\hline Displacement (in) & 5.066 & 8.972 & 5.231 & 0.738 & 8.564 & 12.488 & 8.836 & 1.461 \\
\hline $\begin{array}{c}\text { Percent of } \\
\text { difference with } \\
\text { experiment }(\%)^{1}\end{array}$ & & 77 & 3.25 & 586 & & 71 & 3.07 & 609 \\
\hline
\end{tabular}

In the improved model, when connections were assumed as rigid, the displacement at the peak of the first truss was only 1.461 inches. With simple joints at the location of the braces, the displacement at the peak of the first truss was 12.488 inches. Therefore, the difference between two assumptions was $755 \%$. Although this value is $361 \%$ lower than standard model, $755 \%$ is still a significant percent of difference in models where joint stiffness assumption was changed. Addition of members such as sway bracing and therefore addition of load path in the structure and reinforcement of the loading point by a lateral brace can be the reason a smaller difference value was obtained in the improved model in comparison with the standard model. Similarly, the rigid and simple joint assumptions in the improved model have 505\% and $41 \%$ differences in comparison with experimental results, respectively.

Therefore, in both the standard and improved models, the hinged joint assumption had a lower percent of difference with the experimental results (below 77\%) and provided closer displacement results to the experiment. However, these percent of differences are still large and 
simple and rigid joint assumptions alone are not practical to be used in engineering design of MPCWT structures. Therefore, similar to validation study model in this paper, an analog with combined joint assumptions containing simple and rigid with rotational stiffness values (Semirigid effects) determined in the experiment, should be the most realistic model to be used.

\subsubsection{Load Location}

The results of the load location parametric study are shown in Table 3-7. The location of the load on the fourth truss in the standard model and the third truss on the improved model was used in the validation study. In the standard model, changing the location of the load from the $2^{\text {nd }}$ truss through to the $5^{\text {th }}$ truss, the amount of displacement at the peak of the first truss changed from $8.15 \%$ to $2.07 \%$ compared to the experiment. The experimental displacement value was 5.066 as represented in Table 3-4. Therefore, the percent of difference considering the experimental displacement value (5.066 in) is very low and the greatest difference was only $8 \%$ different. The fourth truss had the greatest displacement value among others. Bracing configuration and the load path that is provided in the structure may is the only reason that the out-of-plane load on the $4^{\text {th }}$ truss deflected the assembly more than other cases and caused greater displacements. Since there was a brace near the loading point in the first truss, then smallest displacement was recorded when load applied to the first truss. Almost the same displacement values were obtained when load location was in the $3^{\text {rd }}$ and $5^{\text {th }}$ truss. In the standard model, maximum axial force $F_{x}$, occurred in the top diagonal bracing and the average force was $1454 \mathrm{lbs}$.

In the improved model, similar to the standard model, no obvious difference in displacement was found, and in general, the range of displacement changes were from $8.61 \%$ to $4.72 \%$ compared to the experiment. The experimental displacement value was 8.564 in as represented in Table 3-4 and as compared to obtained displacements from models almost 5\% 
difference in all of the cases was observed except in the $4^{\text {th }}$ truss. Although percent of differences are greater than the percent of differences obtained in the standard model, but there are still lower than 5\% in three cases which are considered negligible. Similar to the standard model, greatest amount of displacement was obtained when the load was in the $4^{\text {th }}$ truss in the improved model. Appropriate loading paths provided by members to transfer loads in the assembly and unbraced length near the load location could be the reasons for this high displacement. In the improved model, the average maximum axial force $F_{x}$, was $2384 \mathrm{lbs}$ that again occurred in the top diagonal bracing.

Table 3-7- Load location parametric study results

\begin{tabular}{|c|c|c|c|c|c|c|c|c|}
\hline \multirow[b]{2}{*}{ Load location } & \multicolumn{4}{|c|}{ Standard model } & \multicolumn{4}{|c|}{ Improved model } \\
\hline & 2nd & $3 \mathrm{rd}$ & $4 \mathrm{th}^{1}$ & 5 th & 2nd & $3 \mathrm{rd}^{1}$ & 4 th & 5 th \\
\hline Displacement (in) & 4.684 & 4.924 & 5.231 & 4.963 & 8.98 & 8.973 & 9.302 & 8.969 \\
\hline $\begin{array}{l}\text { Percent of difference } \\
\text { with experiment }{ }^{2}\end{array}$ & $8.15 \%$ & $2.88 \%$ & $3.25 \%$ & $2.07 \%$ & $4.85 \%$ & $4.77 \%$ & $8.61 \%$ & $4.72 \%$ \\
\hline
\end{tabular}

The average axial force in the lateral and diagonal braces members is directly related to the magnitude of out-of-plane applied load to the assembly. Therefore, greater average axial force in the members of improved model is the result of greater applied load to the truss assembly. However these axial loads are much lower than tension or compression capacities of members (based on the NDS) and could not cause failures or break in the members itself, but may cause connection failures.

\subsubsection{Truss length}

Parametric study results of the truss length are shown in Table 3-8. As truss length increased, the magnitude of displacement in the peak of the first truss also increased. The amount of displacement in 25 and 30ft. span trusses was similar and was 23.171 and 23.721 inches, 
respectively. These displacements are large for a truss assembly in the construction stage and under an out-of-plane load from FAS. Increasing the distance between truss supports may be the main reason of the increase in displacement values in the longer span trusses. Better reinforcement with additional bracing and different configurations may be required to provide enough strength for a truss assembly with spans larger than 20ft. However, strength of the members was not consider in this study because modeling assumption was linear elastic and therefore only stiffness of the members was considered.

Table 3-8- Truss length parametric study results

\begin{tabular}{ccccc}
\hline Truss Length (ft.) & 13 & 20 & 25 & 30 \\
\hline Displacement (in) & 5.489 & 17.387 & 23.171 & 23.721 \\
\hline
\end{tabular}

As truss length increased, the member axial forces increased as well. The location of maximum axial force was in the middle of the left diagonal bracing and it was the same in all four different lengths tested here. Diagonal bracing in the left side of the trusses in Figure 3-7 had the maximum axial force $F_{x}$, in longitudinal direction of the member, which means critical member in a MPCWT assembly under out-of-plane loads is diagonal braces on the top of the trusses. The trend in the amount of the force in left diagonal braces is proportional with the increasing length of the truss span, as shown in Figure 3-7 and Table 3-9. The difference between A1 brace forces in $13 \mathrm{ft}$. and $30 \mathrm{ft}$. as the trusses which have lowest and greatest axial forces is $104 \%$ that reveals high dependency of axial forces to the increasing span of the truss. As discussed earlier, increasing the distance between truss supports may be the main reason of the increase of axial force in the left lateral brace.

However, the trend in the amount of the force in right lateral brace (B1) is not proportional with the increasing length of the truss span, since $30 \mathrm{ft}$. and $13 \mathrm{ft}$. spans trusses had lower forces 
than the 20ft. and $25 \mathrm{ft}$. span trusses. The increasing trend was followed up to the $25 \mathrm{ft}$. truss, but in the $30 \mathrm{ft}$. truss the forces in B1 eventually decreased. Since the $30 \mathrm{ft}$. truss has more members, the load was distributed among members and smaller portion of forces may be reached to the B1 lateral brace. The greatest axial force in B1 occurred in the $25 \mathrm{ft}$. span truss assembly and the lowest was for $30 \mathrm{ft}$. span trusses, with the difference of $69 \%$. Therefore diagonal bracing seems to be more sensitive to the variation of the truss span length than the lateral bracing, and may need more reinforcement.

Table 3-9- Maximum axial forces in the right lateral brace (lbs.)

\begin{tabular}{c|cccc}
\hline & $13 \mathrm{ft}$. & $20 \mathrm{ft}$. & $25 \mathrm{ft}$. & $30 \mathrm{ft}$ \\
\hline Left diagonal brace, A1 & 1382 & 1920 & 2028 & 2816 \\
\hline Right lateral brace, B1 & 912 & 1424 & 1431 & 847 \\
\hline
\end{tabular}




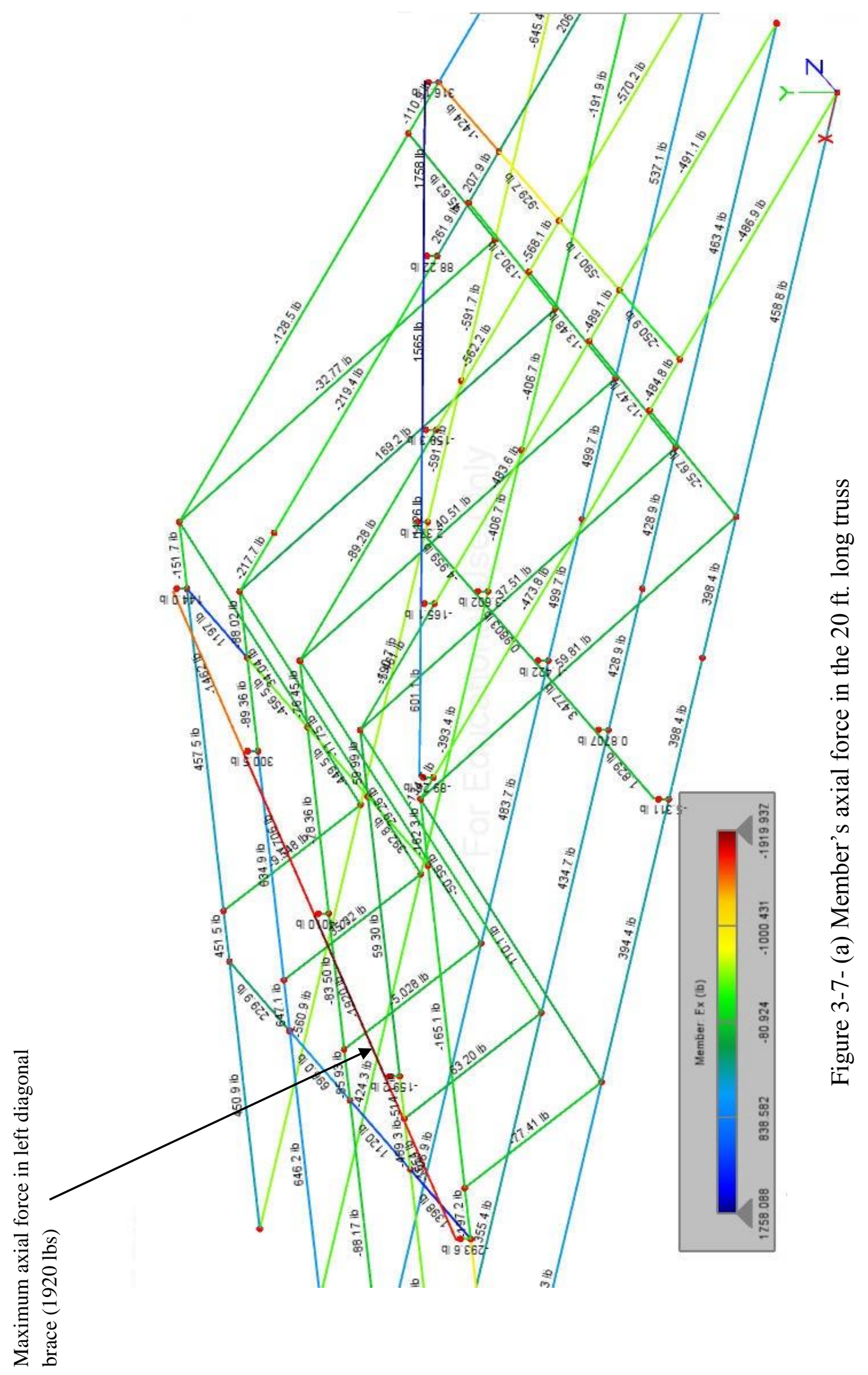




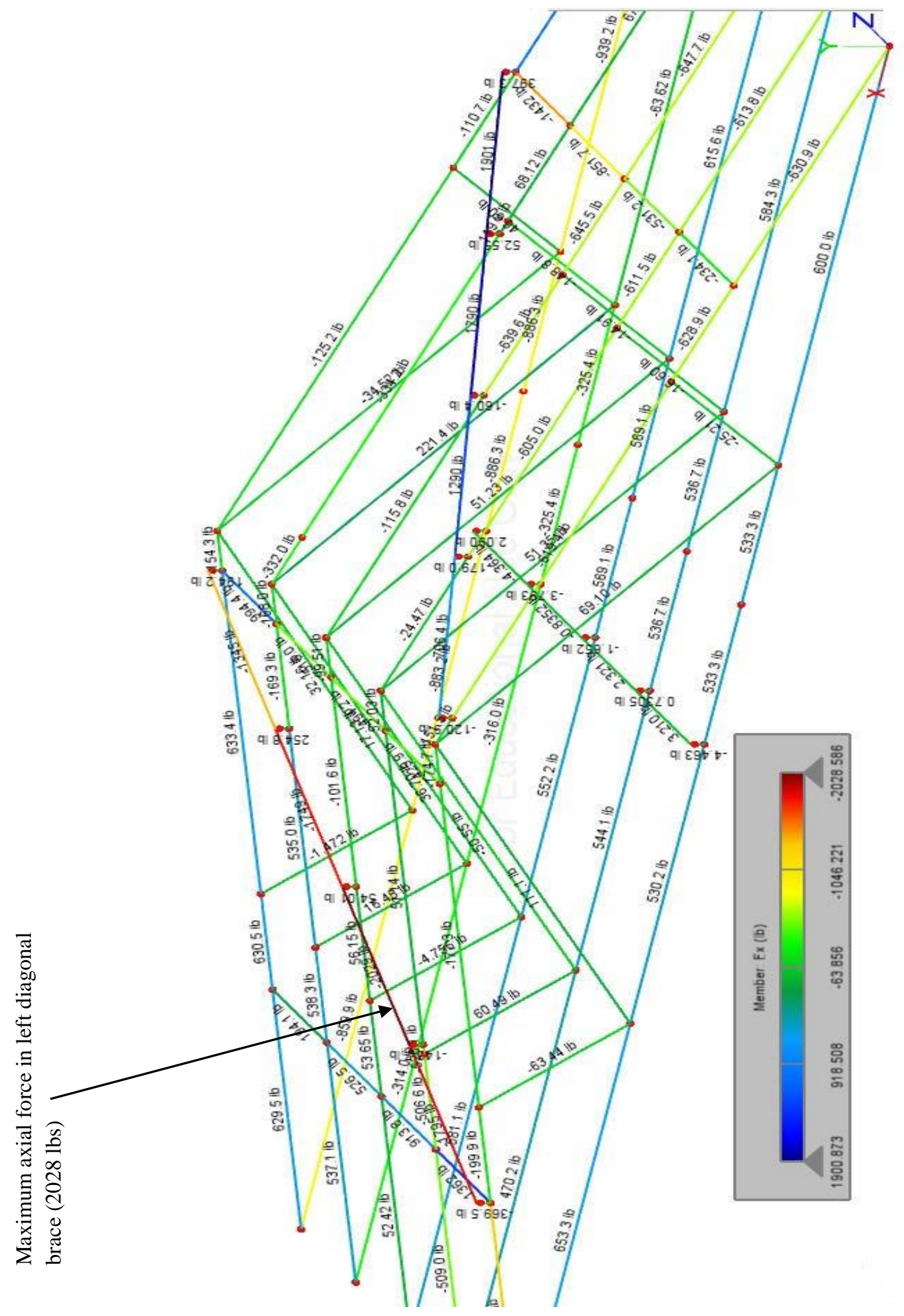

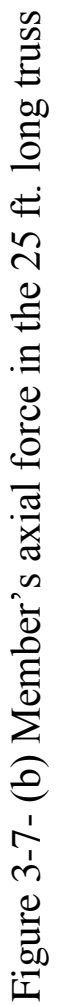




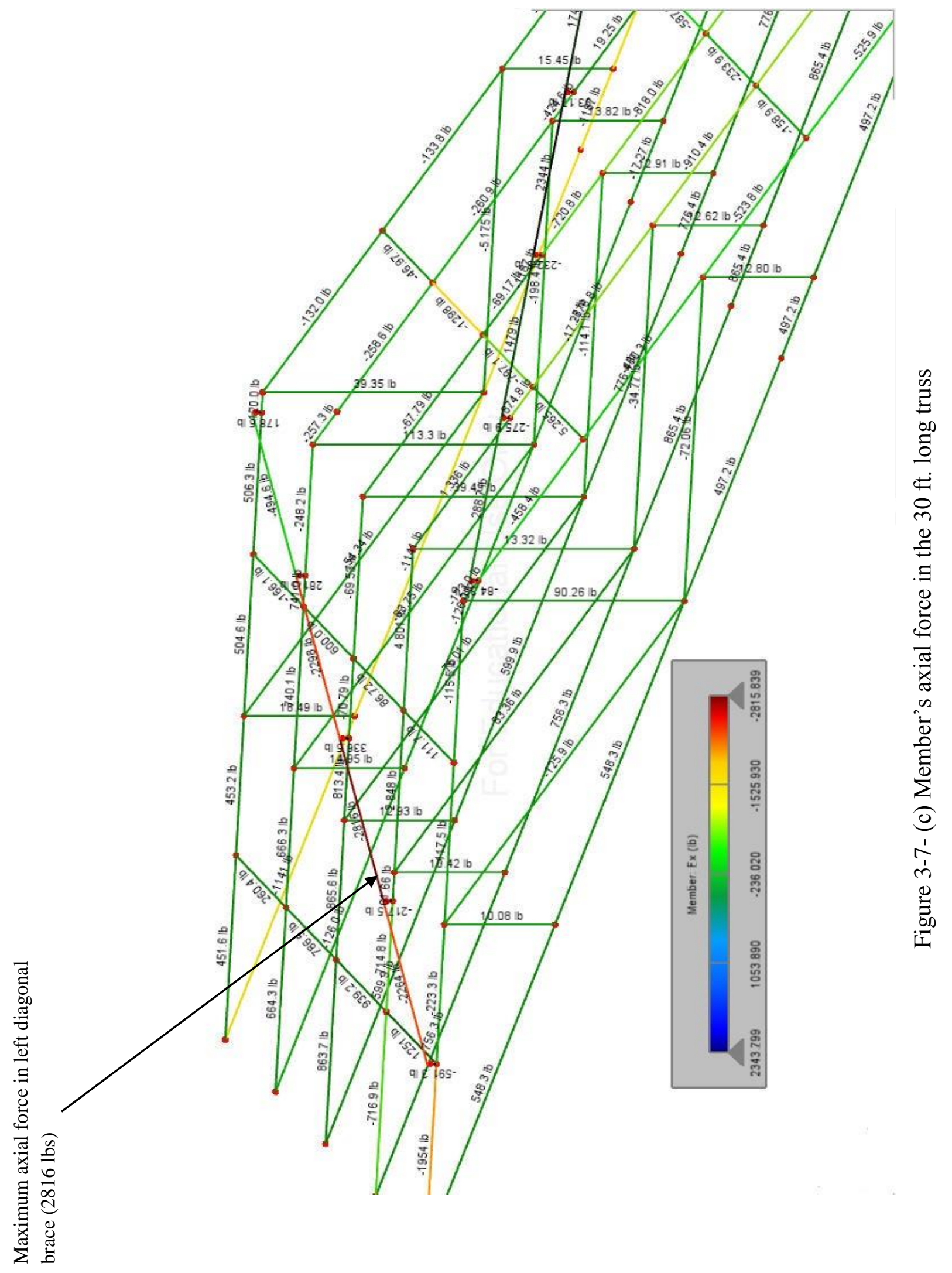


The only members of the trusses in the $30 \mathrm{ft}$. span truss assembly that carried a greater load than $1000 \mathrm{lbs}$, are the whole bottom chord in the last truss and the left top chord near the support in the first truss (Figure 3-7). According to the NDS, these loads did not cause failure in the members. Attachment of the left diagonal bracing to that top chord joint, may bring loads from that critical brace to this member and allow the top chord to tolerate high amount of the axial force. Similar members in $25 \mathrm{ft}$. and $20 \mathrm{ft}$. trusses also showed that are exposed to high amount of load because of the same reason. Therefore, reinforcement of the truss assembly structure connections is recommended in last truss bottom chord and first truss left top chord near to the end support.

\subsection{Conclusion}

The purpose of this paper was to model and validate the MPCWT truss assembly under out-of-plane loads with test results from Morris (2013) using structural analysis software and joint stiffness values obtained in Paper 1. Previous experimental studies measured the loads applied by FAS, truss brace connections and truss-to-wall attachments. Considering rotational stiffness values of truss connection from previous research, two MPCWT assemblies were modeled in Visual Analysis (VA) software and results compared to the experiment first truss deflection. Model was compared to the experimental reports from Morris (2013) for both standard and improved truss assemblies. Good agreement was observed between the model and experimental displacements at the peak of the first truss and the model was validated by less than $4 \%$ difference in displacement values. Then, a parametric study considering joint stiffness, load location and truss length was conducted in VA. Joint stiffness in the truss lateral and diagonal bracing locations was an important parameter that influenced the behavior of the assembly. Maximum deflection was reached when joints were simply assumed as simple connections and minimum deflection was achieved when rigid connection assumption was allotted to the joints in the models. Only a small difference in the 
amount of deflection was found when the location of the anchor was moved in each truss in the assembly. Truss length was also an important parameter that may affect a MPCWT assembly. Longer truss spans ended up to larger deflections and greater axial force in the members. Therefore, proper bracing of trusses for larger spans when attached to FAS is recommended. 


\subsection{Summary}

\subsection{Conclusions}

When a MPCWT assembly is subjected to the out-of-plane loads resulting from FAS, adequate stiffness by the members including trusses, bracing elements and connections are required to prevent collapse of the assembly and provide support for a person that is attached to the structure. Previous research by Morris (2013) on a five truss assembly showed that rotation of the hurricane clips and pull-out of members in lateral and diagonal bracing were the main sources of failure in the structure. Considering time and laboratory space and expenses, modeling of the trusses was considered an appropriate option to investigate the behavior of the different variables including joint stiffness, load location and truss length.

In the first paper, rotational stiffness of truss lateral and diagonal bracing, and truss-wall connections were determined. The rotational stiffness of lateral bracing was 3 times greater than diagonal bracing since horizontal placement of the nails provided good resistance against the load. Pull out and bending of the nails were observed in the experiments. When hurricane clips attached to the direction of applied load the lowest rotational stiffness values among all bracing types tested were recorded and buckling of hurricane clips was observed. While hurricane ties were in tension, the greatest rotational stiffness values were achieved. Addition of the support resistance to resistance of the hurricane tie was the reason of the large rotational stiffness values.

In the second paper, the truss assembly tested by Morris (2013) was modeled in VA software. Results of rotational stiffness tests were used for semi-rigid assumption of truss connections in the MPCWT assembly analysis. Validation of both the Morris standard and improved models showed that the molding outcomes are in good agreement with experimental results. After validation, a parametric study considering three parameters (truss joint stiffness, FAS 
location and truss span length) was conducted. Joint stiffness was an effective parameter, which can influence the deflection of the MPCWT, if the correct assumption (semi-rigid effect) is ignored. It was determined that the location of FAS is not an important parameter in the behavior of the assembly. Truss span length was another critical parameter that can affect the behavior of the assembly, since larger spans produced larger deflection in the MPCWT. 


\subsection{Limitations of Study}

There are several limitations for this study that are outlined as follows:

- Stiffness of joints in bracing locations was determined with simplicity and assuming one end of the member as free. In real condition member is fixed-end in both side.

- The Validation study was limited to Morris (2013) work. It was not the scope of this research to conduct a large scale experiment for validation study.

- During modeling, truss joints were assumed as simple and rigid only.

- The horizontal test performed was used for model validation. If data from other loading conditions as a result of a fall was available, the validation study could be expanded.

- Modeling only assumed elastic behavior. Considering inelastic behavior of members and joints, can provide more accurate modeling results, but may need more computational expenses.

- Additional locations for displacement measurement should be used in experimental works to have enough displacement measurements in order to compare with the model outcomes, and therefore have better validation study. 


\subsection{Future Study}

For future research, larger scale experimental testing under an impact load similar to an actual fall is recommended with multiple measurements of displacement. Therefore models can be exposed to include impact loads. Impact loads more closely resemble the actual loads of a person falling than static loads.

Joint stiffness in truss member attachments should be determined in order to create more accurate modeling. Analytical solutions of the truss metal plate connection also exist in the literature for validation of analytical and experimental results. Other kinds of joint stiffness tests according to various types of connections in MPCWT assembly should be performed to create a database of rotational stiffness values of the wood truss connections, both truss plate connection and bracing locations.

The behavior of the joints in moment-rotation diagrams was nonlinear. Using precise analysis tools such as finite element method (FEM), joints separately can be modeled with appropriate elements and assumptions. Nonlinear FE analysis with accurate nonlinear momentrotation diagrams need to be performed for both lateral and diagonal bracing joints individually and truss assembly as well.

Additional loading conditions such as in-plane loading or mixed, in-plane or out-of-plane loading can also be performed in the models to examine how loading conditions affect the MPCWT assembly. Loading condition is an important and complicated part of safety research and determination of a better method that more closely simulates an actual fall is paramount to model realistic conditions. 


\section{References}

AISI/COFS. Standard for cold-formed steel framing — Truss design, Revision of

AISI/COFS/TRUSS 2000. American Iron and Steel Institute, Committee on Framing Standards (COFS); 2001 [1 $^{\text {st }}$ printing June 2002].

AISI. Commentary on the standard for cold-formed steel framing — Truss design. American Iron and Steel Institute. Committee on Framing Standards (COFS); 2001 [1st printing June 2002].

ASTM D 2395 - 07a. Standard test method for specific gravity of wood and wood-based materials. American Society of Testing and Materials; 2008.

ASTM D 4442 - 92. Standard test method for direct moisture content measurement of wood and wood-based materials. American Society of Testing and Materials; 2003.

ASTM D5457 - 10. Standard specification for computing reference resistance of wood-based materials and structural connections for load and resistance factor design. American Society of Testing and Materials; 2010.

BCSI, Building Components Safety Information. Structural Building Components Association (SBCA) and Truss Plate Institute (TPI). Guide to good practice for handling, installing, restraining and bracing of MPC wood trusses. 2012. SBCA. Madison, WI.

BLS (Bureau of Labor Statistics) News Release. 2012. National Census of Fatal Occupational Injuries in 2011. Accessed February 5, 2013 from http://www.bls.gov/news.release/pdf/cfoi.pdf

Barbari M. Cavalli A. Fiorineschi L. Monti M. Togni M. Innovative connection in wood trusses. Construction and Building Materials. 2014. 66: 654-663.

Bohnhoff D. R. Lateral movement of unbraced trusses during construction. In ASAE Annual International Meeting. 2001.13. Sacramento, CA: American Society of Agricultural and Biological Engineers.

Center to Protect Workers' Rights (CPWR). 2014. Stop Construction Falls Campaign. http://stopconstructionfalls.com/ Accessed July 5, 2014.

DeRenzis A. Kochkin V. Wang X. Evaluation of the lateral performance of roof truss-to-wall connections in light-frame wood systems. August 2012. Forest Products Laboratory. U.S Department of Agriculture.

Ellis, J. N. Introduction to fall protection. Des Plaines, Ill. 2011, American Society of Safety Engineers. 
Gupta R. Miller T. Dung DR. Practical solution to wood truss assembly design problems. Practice Periodical on Structural Design and Construction. 2004. ACSE Journals. 54-60.

Gupta R. System behavior of wood truss assemblies. Timber Construction. 2005. 7:183-193.

Gupta R. Gebremedhin K. G. Cooke J.R. Analysis of metal-plate-connected wood trusses with semi-rigid joints. American Society of Agricultural Engineers. 1992. 35: 1011-1018.

Gupta R. Vatovec M. Miller TH. Metal-plate-connected wood joints: A literature review. Research Contribution 13, Forest Research Laboratory, Oregon State University, Corvallis, OR97331, 1996.

Hindman, D. Morris, J. Mohamadzadeh, M. Koch, L. Angles, J. Smith-Jackson, T. Personal fall arrest system anchors in residential construction. Wood Design Focus. 2013. 23(1): 20-27.

Hussein R. Parametric investigation of the buckling performance of metal-plate-connected joints. Advances in Engineering Software. 2000. 31: 45-56.

Hagan H. A. Common causes of collapse of metal-plate-connected wood roof trusses. J. Perform. Constr. Facil. 1993. 7(4):225-234.

IES, Inc. Visual Analysis software producer. Accessed January 9, 2013 online at WWW.iesweb.com.

Kaskutas V. Dale A. M. Nolan J. Lipscomb H. J. Evanoff B. Fall Hazard Control Observed on Residential Construction Sites. American Journal of Industrial Medicine. 2009. 52(6): 491-499.

Koch L. M. Hindman D. P. Smith-Jackson T. Metal plate connected wood trusses exposed to out of plane lateral loads. Journal of Architectural Engineering. 2014. Submitted for publication.

Koch L. Lateral capacity of roof trusses loaded by personal fall arrest system. Unpublished report. Virginia Tech. Department of Sustainable Biomaterials. 2012. Blacksburg. Virginia.

Kanerva P. Peltola S. Vesa J. Design methods for utilization of rotational stiffness of mechanical joints on the design of timber structures. Proceeding of World Conference of Timber Engineering (WCTE). 2004.

Kassimali A. Structural Analysis. Fourth edition. 2010. Cengage Learning.

Leatherman B. Professional engineer at Timber Tech Engineering. Inc. Email consultation. January 20. 2014.

Morris .C. J. "Analysis of Anchors and Bracing Configurations with Personal Fall Arrest Systems in Residential Construction.” M.Sc. thesis. Virginia Tech. Blacksburg, Virginia. 2013. 
National design specification for wood construction (NDS). 2012 Edition. American Wood Council (AWC), American Forest \& Paper Association, Inc.

OSHA. 2010a. STD 03-11-002 Compliance Guidance for Residential Construction.

Occupational Safety and Health Administration.

https://www.osha.gov/pls/oshaweb/owadisp.show_document?p_table=DIRECTIVES\&p_id=475

5. Accessed June 22, 2013.

OSHA, Occupational Safety and Health Administration. 2011b. Safety and Health Regulations in Construction 1926.501. Duty to have fall protection.

http://www.osha.gov/pls/oshaweb/owadisp.show_document?p_table=STANDARDS\&p_id=107

57. Accessed June 23, 2013.

Stehn L. Borjes K. The influence of nail ductility on the load capacity of a glulam truss structure. Engineering Structures. 2004. 26: 809-816.

Song X. Stability and reliability analysis of metal plate connected wood truss assemblies. Ph.D. thesis submitted to the University of British Columbia. Vancouver, Canada. 2009.

Song X. Lam F. Stability analysis of metal-plate-connected wood truss assemblies. Journal of Structural Engineering. 2012. 138: 1110-1119.

Šilih S. Kravanja S. Premrov M. Shape and discrete sizing optimization of timber trusses by considering of joint flexibility. Advances in Engineering Software, 2010. 41(2): p. 286-294.

Šilih S. Premrov M. Kravanja S. Optimum design of plane timber trusses considering joint flexibility. Engineering Structures. 2005 27(1): 145-154.

Underwood C. Woeste F. Dolan D. Holzer, S. Permanent bracing design for MPC wood roof truss webs and chords. Forest products journal. 2001. 51:73-81.

Wolfe R.W. McCarthy M. Structural performance of light-frame roof assemblies. I: Truss assemblies designed for high variability and wood failure. 1989. Research paper FPL-RP-492, U.S. Department of Agriculture, Madison, WI.

Wolfe R.W. LaBissoniere T. Structural performance of ligh-frame roof assemblies. II: Conventional truss assemblies. 1991. Research paper FPL-RP-499, U.S. Department of Agriculture, Madison, WI.

Wolfe R.W. Percival D. H. Moody R.C. Strength and stiffness of light-frame sloped trusses. 1986. Research paper FPL 471. U.S. Department of Agriculture, Madison, WI.

Zaharia R. Dubina D. Stiffness of joints in bolted connected cold-formed steel trusses. Journal of Constructional Steel Research. 2006. 62(3): p. 240-249. 


\section{APPENDIXA}

Rotational Stiffness of Lateral Bracing Test Data

\section{1- Lateral Bracing}

\begin{tabular}{|c|c|c|c|c|c|}
\hline $\begin{array}{c}\text { Specimen } \\
\#\end{array}$ & $\begin{array}{l}\text { MAX Load } \\
\text { (lb) }\end{array}$ & Displacement (in) & Theta $\theta$ (radians) & $\begin{array}{c}\text { Theta } \theta \\
\text { (Degree) }\end{array}$ & $\begin{array}{c}\mathrm{K} \\
\text { (lb.in/deg) }\end{array}$ \\
\hline 1 & 34.439 & 1.554 & 0.078 & 4.444 & 154.984 \\
\hline 2 & 14.351 & 1.964 & 0.098 & 5.607 & 51.188 \\
\hline 5 & 15.869 & 1.238 & 0.062 & 3.541 & 89.625 \\
\hline 6 & 21.373 & 1.344 & 0.067 & 3.845 & 111.159 \\
\hline 7 & 17.139 & 1.509 & 0.075 & 4.315 & 79.438 \\
\hline 8 & 13.872 & 1.531 & 0.076 & 4.376 & 63.396 \\
\hline 9 & 17.247 & 1.192 & 0.060 & 3.411 & 101.125 \\
\hline 10 & 18.445 & 1.257 & 0.063 & 3.595 & 102.617 \\
\hline 11 & 19.431 & 1.692 & 0.084 & 4.835 & 80.382 \\
\hline 12 & 19.533 & 1.461 & 0.073 & 4.178 & 93.507 \\
\hline 13 & 15.768 & 1.997 & 0.100 & 5.703 & 55.295 \\
\hline 14 & 18.652 & 1.274 & 0.064 & 3.644 & 102.381 \\
\hline 16 & 22.542 & 1.861 & 0.093 & 5.315 & 84.822 \\
\hline 17 & 18.256 & 1.471 & 0.073 & 4.205 & 86.822 \\
\hline 18 & 16.769 & 1.076 & 0.054 & 3.079 & 108.932 \\
\hline 19 & 14.274 & 1.949 & 0.097 & 5.566 & 51.292 \\
\hline \multirow[t]{4}{*}{20} & 20.030 & 1.338 & 0.067 & 3.827 & 104.674 \\
\hline & & & & Average & 89.51 \\
\hline & & & & S.D & 26.04 \\
\hline & & & & $\mathrm{COV}$ & $29 \%$ \\
\hline
\end{tabular}




\section{2- Diagonal Bracing}

\begin{tabular}{|c|c|c|c|c|c|}
\hline $\begin{array}{c}\text { Specimen } \\
\#\end{array}$ & MAX Load (lb) & Displacement (in) & Theta $\theta$ (radians) & Theta $\theta$ (Degree) & K (lb.in/deg) \\
\hline 1 & 13.319 & 5.746 & 0.280 & 16.028 & 16.619 \\
\hline 2 & 14.097 & 3.681 & 0.182 & 10.430 & 27.032 \\
\hline 3 & 13.590 & 1.954 & 0.097 & 5.580 & 48.706 \\
\hline 4 & 11.312 & 5.692 & 0.277 & 15.887 & 14.241 \\
\hline 5 & 15.552 & 5.578 & 0.272 & 15.585 & 19.958 \\
\hline 6 & 11.825 & 5.886 & 0.286 & 16.400 & 14.420 \\
\hline 7 & 10.937 & 5.954 & 0.289 & 16.579 & 13.194 \\
\hline 8 & 14.282 & 5.918 & 0.288 & 16.483 & 17.329 \\
\hline 9 & 11.604 & 5.944 & 0.289 & 16.551 & 14.022 \\
\hline 12 & 10.620 & 5.692 & 0.277 & 15.887 & 13.370 \\
\hline 13 & 10.920 & 5.910 & 0.287 & 16.463 & 13.266 \\
\hline 14 & 18.495 & 5.244 & 0.256 & 14.692 & 25.177 \\
\hline 15 & 14.287 & 5.906 & 0.287 & 16.451 & 17.369 \\
\hline 16 & 14.858 & 5.489 & 0.268 & 15.347 & 19.363 \\
\hline 17 & 20.177 & 3.079 & 0.153 & 8.753 & 46.105 \\
\hline 19 & 17.481 & 5.904 & 0.287 & 16.446 & 21.259 \\
\hline \multirow[t]{4}{*}{20} & 18.769 & 5.825 & 0.283 & 16.239 & 23.117 \\
\hline & & & & Average & 21.44 \\
\hline & & & & S.D & 10.66 \\
\hline & & & & $\mathrm{COV}$ & $50 \%$ \\
\hline
\end{tabular}




\section{APPENDIX B}

Rotational Stiffness of Truss-Wall Connection Test Data

\section{1- Hurricane Clip In Tension}

\begin{tabular}{|c|c|c|c|}
\hline $\begin{array}{c}\text { Specimen } \\
\#\end{array}$ & Max Torque (ib-in) & Max rotation (degree) [near support] & $\mathrm{K}$ \\
\hline 1 & 1637.3 & 24.525 & 66.759 \\
\hline 2 & 1693.6 & 17.209 & 98.415 \\
\hline 3 & 1246.84 & 11.722 & 106.369 \\
\hline 4 & 1225.96 & 8.0268 & 152.733 \\
\hline 5 & 1850.59 & 17.193 & 107.637 \\
\hline 6 & 1599.71 & 18.723 & 85.441 \\
\hline 7 & 1629.39 & 15.888 & 102.555 \\
\hline 8 & 1214.35 & 13.898 & 87.376 \\
\hline 9 & 1783.48 & 15.380 & 115.961 \\
\hline 10 & 1546.56 & & 18.817 \\
\hline & & & 82.190 \\
\hline & & Average & 100.54 \\
\hline & STD & 23.41 \\
\hline & COV & $23 \%$ \\
\hline & & & \\
\hline
\end{tabular}




\section{2- Hurricane Clip In Compression}

\begin{tabular}{|c|c|c|c|}
\hline $\begin{array}{c}\text { Specimen } \\
\#\end{array}$ & Max Torque (ib-in) & Max rotation (degree) [near support] & K \\
\hline 1 & 62.15 & 19.810 & 3.137 \\
\hline 2 & 56.339 & 24.030 & 2.345 \\
\hline 3 & 67.4148 & 25.126 & 2.683 \\
\hline 4 & 106.891 & 22.412 & 4.769 \\
\hline 5 & 62.07 & 22.371 & 2.775 \\
\hline 6 & 33.049 & 22.277 & 1.484 \\
\hline 7 & 119.002 & 23.343 & 5.098 \\
\hline 8 & 61.784 & 24.369 & 2.535 \\
\hline 9 & 64.922 & 23.437 & 2.770 \\
\hline 10 & 66.539 & & 21.882 \\
\hline & & & 3.041 \\
\hline & & Average & 3.06 \\
\hline & & STD & 1.09 \\
\hline & & COV & $36 \%$ \\
\hline
\end{tabular}




\section{APPENDIX C}

Moisture Content and Specific Gravity Test Data: ASTM D 4432 and ASTM D 2395

\begin{tabular}{|c|c|c|c|c|c|}
\hline $\begin{array}{c}\text { Specimen } \\
\#\end{array}$ & Wet & $\begin{array}{c}\text { Dry } \\
\text { Weight }\end{array}$ & $\begin{array}{c}\text { Wax } \\
\text { Weight }\end{array}$ & Moisture Content & Specific Gravity \\
\hline $0-1$ & 49.53 & 45.32 & 84.81 & 9.289 & 0.534 \\
\hline $0-2$ & 40.06 & 37.11 & 82.09 & 7.949 & 0.452 \\
\hline $0-3$ & 41.25 & 38.2 & 84.54 & 7.984 & 0.452 \\
\hline $0-4$ & 38.01 & 35.28 & 81.33 & 7.738 & 0.434 \\
\hline $0-5$ & 44.14 & 40.6 & 81.67 & 8.719 & 0.497 \\
\hline $0-6$ & 41.58 & 38.35 & 82.94 & 8.422 & 0.462 \\
\hline $0-7$ & 41.55 & 38.37 & 81.94 & 8.288 & 0.468 \\
\hline $0-8$ & 44.79 & 41.29 & 84.26 & 8.477 & 0.490 \\
\hline $0-9$ & 44.32 & 40.93 & 77.84 & 8.282 & 0.526 \\
\hline $0-10$ & 49.71 & 45.96 & 84.23 & 8.159 & 0.546 \\
\hline $0-11$ & 39.17 & 35.98 & 85.31 & 8.866 & 0.422 \\
\hline $0-12$ & 42.6 & 39.39 & 79.53 & 8.149 & 0.495 \\
\hline $0-13$ & 38.41 & 35.58 & 83.93 & 7.954 & 0.424 \\
\hline $0-14$ & 42.85 & 39.58 & 79.19 & 8.262 & 0.500 \\
\hline $0-15$ & 44.72 & 40.66 & 81.32 & 9.985 & 0.500 \\
\hline $0-16$ & 38.24 & 35.06 & 79.44 & 9.070 & 0.441 \\
\hline $0-17$ & 41.3 & 38.22 & 81.86 & 8.059 & 0.467 \\
\hline $0-18$ & 43.66 & 40.2 & 81.05 & 8.607 & 0.496 \\
\hline $0-19$ & 38.14 & 35.16 & 80.72 & 8.476 & 0.436 \\
\hline \multirow[t]{3}{*}{$0-20$} & 36.9 & 34.06 & 82.68 & 8.338 & 0.412 \\
\hline & & & Mean & 8.454 & 0.473 \\
\hline & & & & 0.532 & 0.039 \\
\hline T-SP-1 & 42 & 38.77 & 78.16 & 8.331 & 0.496 \\
\hline T-SP-2 & 41.46 & 38.54 & 83.75 & 7.577 & 0.460 \\
\hline T-Sp-3 & 45.65 & 42.47 & 84.1 & 7.488 & 0.505 \\
\hline T-SP-4 & 38 & 35.6 & 78.84 & 6.742 & 0.452 \\
\hline T-SP-5 & 38.59 & 36 & 83.65 & 7.194 & 0.430 \\
\hline T-SP-6 & 37.45 & 35.02 & 75.6 & 6.939 & 0.463 \\
\hline T-SP-7 & 45.47 & 41.75 & 82.2 & 8.910 & 0.508 \\
\hline T-SP-8 & 39.88 & 37.44 & 86.18 & 6.517 & 0.434 \\
\hline T-SP-9 & 44.55 & 41.71 & 84.7 & 6.809 & 0.492 \\
\hline T-SP-10 & 43.49 & 40.59 & 77.75 & 7.145 & 0.522 \\
\hline T-SP-11 & 36.38 & 34.02 & 87.01 & 6.937 & 0.391 \\
\hline
\end{tabular}




\begin{tabular}{|c|c|c|c|c|c|}
\hline T-SP-12 & 38.61 & 36.27 & 83.75 & 6.452 & 0.433 \\
\hline T-SP-13 & 40.93 & 38.32 & 76.5 & 6.811 & 0.501 \\
\hline T-SP-14 & 34.29 & 32.1 & 85.36 & 6.822 & 0.376 \\
\hline T-SP-15 & 26.21 & 24.5 & 64.39 & 6.980 & 0.380 \\
\hline T-SP-16 & 38.84 & 36.13 & 66.57 & 7.501 & 0.543 \\
\hline T-SP-17 & 44.72 & 38.7 & 76.89 & 15.556 & 0.503 \\
\hline T-SP-18 & 39.72 & 37.26 & 85.9 & 6.602 & 0.434 \\
\hline T-SP-19 & 39 & 36.25 & 83.77 & 7.586 & 0.433 \\
\hline \multirow[t]{3}{*}{ T-SP-20 } & 41.6 & 38.8 & 83.58 & 7.216 & 0.464 \\
\hline & & & Mean & 7.606 & 0.461 \\
\hline & & & & 1.966 & 0.047 \\
\hline T-SY-1 & 36.33 & 34.13 & 81.88 & 6.446 & 0.417 \\
\hline T-SY-2 & 47.87 & 45 & 86.42 & 6.378 & 0.521 \\
\hline T-SY-3 & 52.8 & 49.52 & 86.99 & 6.624 & 0.569 \\
\hline T-SY-4 & 50.71 & 47.57 & 88.86 & 6.601 & 0.535 \\
\hline T-SY-5 & 40.14 & 37.63 & 83.01 & 6.670 & 0.453 \\
\hline T-SY-6 & 42.98 & 40.19 & 85.15 & 6.942 & 0.472 \\
\hline T-SY-7 & 38.29 & 35.85 & 82.75 & 6.806 & 0.433 \\
\hline T-SY-8 & 36.18 & 34.03 & 82.64 & 6.318 & 0.412 \\
\hline T-SY-9 & 37.98 & 35.6 & 86.55 & 6.685 & 0.411 \\
\hline T-SY-10 & 48.1 & 45.12 & 84.6 & 6.605 & 0.533 \\
\hline T-SY-11 & 48.43 & 45.4 & 87.15 & 6.674 & 0.521 \\
\hline T-SY-12 & 47.79 & 44.2 & 89.32 & 8.122 & 0.495 \\
\hline T-SY-13 & 37.33 & 35.07 & 84.47 & 6.444 & 0.415 \\
\hline T-SY-14 & 49.73 & 46.66 & 85.53 & 6.580 & 0.546 \\
\hline T-SY-15 & 48.79 & 45.72 & 82.94 & 6.715 & 0.551 \\
\hline T-SY-16 & 48.62 & 45.63 & 86.85 & 6.553 & 0.525 \\
\hline T-SY-17 & 43.09 & 40.44 & 84.15 & 6.553 & 0.481 \\
\hline T-SY-18 & 46.19 & 43.31 & 87.2 & 6.650 & 0.497 \\
\hline T-SY-19 & 55.27 & 51.49 & 88.02 & 7.341 & 0.585 \\
\hline \multirow[t]{3}{*}{ T-SY-20 } & 51.79 & 48.29 & 85.4 & 7.248 & 0.565 \\
\hline & & & Mean & 6.748 & 0.497 \\
\hline & & & & 0.412 & 0.057 \\
\hline B-SP-1 & 38.3 & 35.7 & 84.08 & 7.283 & 0.425 \\
\hline B-SP-2 & 38.09 & 35.66 & 81.91 & 6.814 & 0.435 \\
\hline B-SP-3 & 44 & 40.94 & 84.39 & 7.474 & 0.485 \\
\hline B-SP-4 & 43.37 & 40.11 & 79.73 & 8.128 & 0.503 \\
\hline
\end{tabular}




\begin{tabular}{|c|c|c|c|c|c|}
\hline B-SP-5 & 35.21 & 32.88 & 84.41 & 7.086 & 0.390 \\
\hline B-SP-6 & 40.92 & 37.94 & 85.24 & 7.855 & 0.445 \\
\hline B-SP-7 & 41.21 & 38.42 & 85.45 & 7.262 & 0.450 \\
\hline B-SP-8 & 39.06 & 36.01 & 83.74 & 8.470 & 0.430 \\
\hline B-SP-9 & 43.38 & 40.41 & 81.54 & 7.350 & 0.496 \\
\hline B-SP-10 & 43.08 & 40.08 & 81.1 & 7.485 & 0.494 \\
\hline B-SP-11 & 39.39 & 36.61 & 85.46 & 7.594 & 0.428 \\
\hline B-SP-12 & 35.07 & 32.67 & 83.91 & 7.346 & 0.389 \\
\hline B-SP-13 & 38.76 & 36.04 & 83.96 & 7.547 & 0.429 \\
\hline B-SP-14 & 43.78 & 41.78 & 80.97 & 4.787 & 0.516 \\
\hline B-SP-15 & 40.76 & 38.02 & 86.73 & 7.207 & 0.438 \\
\hline B-SP-16 & 43.12 & 39.82 & 86.63 & 8.287 & 0.460 \\
\hline B-SP-17 & 44.82 & 41.19 & 83.26 & 8.813 & 0.495 \\
\hline B-SP-18 & 40.03 & 37.12 & 84.57 & 7.839 & 0.439 \\
\hline B-SP-19 & 35.24 & 32.77 & 84.56 & 7.537 & 0.388 \\
\hline B-SP-20 & 39.98 & 37.31 & 86.68 & 7.156 & 0.430 \\
\hline & & & Mean & 7.466 & 0.448 \\
\hline & & & & 0.803 & 0.039 \\
\hline B-SY-1 & 47.72 & 44.78 & 85.39 & 6.565 & 0.524 \\
\hline B-SY-2 & 47.7 & 44.73 & 91.94 & 6.640 & 0.487 \\
\hline B-SY-3 & 46.8 & 43.82 & 85.9 & 6.801 & 0.510 \\
\hline B-SY-4 & 45.09 & 42.29 & 86.89 & 6.621 & 0.487 \\
\hline B-SY-5 & 38.9 & 36.46 & 89.92 & 6.692 & 0.405 \\
\hline B-SY-6 & 37.03 & 34.69 & 86.44 & 6.745 & 0.401 \\
\hline B-SY-7 & 39.62 & 37.09 & 88.49 & 6.821 & 0.419 \\
\hline B-SY-9 & 39.17 & 36.57 & 84.73 & 7.110 & 0.432 \\
\hline B-SY-10 & 39.04 & 36.49 & 85.37 & 6.988 & 0.427 \\
\hline B-SY-11 & 37.62 & 35.14 & 84.1 & 7.057 & 0.418 \\
\hline B-SY-12 & 40.04 & 37.28 & 86.1 & 7.403 & 0.433 \\
\hline B-SY-13 & 45.71 & 42.74 & 84.14 & 6.949 & 0.508 \\
\hline B-SY-14 & 44.78 & 41.94 & 84.77 & 6.772 & 0.495 \\
\hline B-SY-16 & 47.5 & 44.38 & 87.71 & 7.030 & 0.506 \\
\hline B-SY-17 & 38.27 & 35.91 & 87.47 & 6.572 & 0.411 \\
\hline B-SY-18 & 45.69 & 42.68 & 83.74 & 7.052 & 0.510 \\
\hline B-SY-19 & 44.84 & 41.94 & 88.18 & 6.915 & 0.476 \\
\hline B-SY-20 & 46.7 & 43.79 & 82.4 & 6.645 & 0.531 \\
\hline
\end{tabular}




\begin{tabular}{|c|c|c|c|c|c|}
\hline & & & Mean & 6.854 & 0.466 \\
\hline & & & & 0.226 & 0.046 \\
\hline & & & & & SP \\
\hline & & & & SPF & 7.35 \\
\hline & & & Average MC & 7.54 & 0.48 \\
\hline & & & Average SG & 0.45 & $5 \%$ \\
\hline & & & COV (MC) & $18 \%$ & $10 \%$ \\
\hline
\end{tabular}

